\title{
Differential reactivity of closely related zinc(II)-binding metallothioneins from the plant Arabidopsis thaliana
}

\author{
Hasan T. Imam ${ }^{1,2} \cdot$ Claudia A. Blindauer ${ }^{1}$ \\ Received: 2 October 2017 / Accepted: 12 November 2017 / Published online: 7 December 2017 \\ (c) The Author(s) 2017. This article is an open access publication
}

\begin{abstract}
The dynamics of metal binding to and transfer from metalloproteins involved in metal homeostasis are important for understanding cellular distribution of metal ions. The dicotyledonous plant Arabidopsis thaliana has two type 4 seed-specific metallothionein homologues, MT4a and MT4b, with likely roles in zinc(II) homeostasis. These two metallothioneins are $84 \%$ identical, with full conservation of all metal-binding cysteine and histidine residues. Yet, differences in their spatial and temporal expression patterns suggested divergence in their biological roles. To investigate whether biological functions are reflected in molecular properties, we compare aspects of zinc(II)-binding dynamics of full-length MT4a and MT4b, namely the $\mathrm{pH}$ dependence of zinc(II) binding and protein folding, and zinc(II) transfer to the chelator EDTA. UV-Vis and NMR spectroscopies as well as native electrospray ionisation mass spectrometry consistently showed that transfer from $\mathrm{Zn}_{6} \mathrm{MT} 4 \mathrm{a}$ is considerably faster than from $\mathrm{Zn}_{6} \mathrm{MT} 4 \mathrm{~b}$, with pseudo-first-order rate constants for the fastest observed step of $k_{\text {obs }}=2.8 \times 10^{-4} \mathrm{~s}^{-1}$ (MT4b) and $k_{\text {obs }}=7.5 \times 10^{-4} \mathrm{~s}^{-1}$ (MT4a) $(5 \mu \mathrm{M}$ protein, $500 \mu \mathrm{M}$ EDTA, $25 \mathrm{mM}$ Tris buffer, pH 7.33, 298 K). 2D heteronuclear NMR experiments allowed locating the most labile zinc(II) ions in domain II for both proteins. 3D homology models suggest that reactivity of this domain is governed by the local environment around the mononuclear $\mathrm{Cys}_{2} \mathrm{His}_{2}$ site that is unique to type $4 \mathrm{MTs}$. Non-conservative amino acid substitutions in this region affect local electrostatics as well as whole-domain dynamics, with both effects rendering zinc(II) ions bound to MT4a more reactive in metal transfer reactions. Therefore, domain II of MT4a is well suited to rapidly release its bound zinc(II) ions, in broad agreement with a previously suggested role of MT4a in zinc(II) transport and delivery to other proteins.
\end{abstract}

Keywords Nuclear magnetic resonance $\cdot$ Mass spectrometry $\cdot$ Zinc $\cdot$ Metallothionein $\cdot$ Metal homeostasis

\section{Abbreviations}

EDTA Ethylene-diamine-tetraacetic acid

ESI-MS Electrospray ionisation mass spectrometry

HSQC Heteronuclear single quantum coherence

ICP-OES Inductively coupled plasma-optical emission spectroscopy

This study is dedicated, with respect, gratitude, and affection, to Prof. Dr. Helmut Sigel, on occasion of his 80th birthday.

Electronic supplementary material The online version of this article (https://doi.org/10.1007/s00775-017-1516-6) contains supplementary material, which is available to authorized users.

Claudia A. Blindauer

c.blindauer@warwick.ac.uk

1 Department of Chemistry, The University of Warwick, Coventry CV4 7AL, UK

2 School of Chemistry, University of St. Andrews, St. Andrews KY16 9ST, UK

$\begin{array}{ll}\text { MT } & \text { Metallothionein } \\ \text { NMR } & \text { Nuclear magnetic resonance } \\ \text { NOESY } & \begin{array}{l}\text { Nuclear Overhauser enhancement } \\ \text { spectroscopy }\end{array} \\ \text { pMT } & \text { Plant metallothionein } \\ \text { TOCSY } & \text { Total correlation spectroscopy }\end{array}$

\section{Introduction}

The unique importance of the essential micronutrient zinc(II) to the health of all organisms is increasingly recognised [1], with the number of confirmed and predicted zinc(II)-requiring proteins still on the rise [2]. The pervasive utilisation of zinc(II) in biological systems renders it a socalled type 2 nutrient [3], which means that its deficiency impacts on a multitude of physiological processes. This is not only true for animals and man [4-6], but also for plants $[7,8]$. 


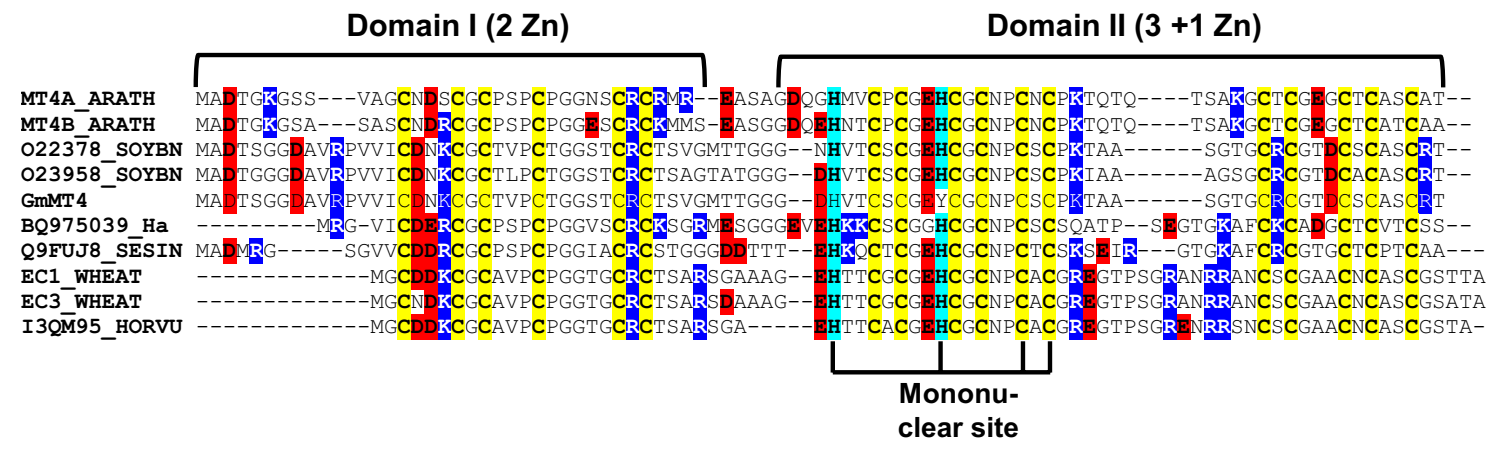

Fig. 1 Sequences of Arabidopsis thaliana MT4a and MT4b (rows 1 and 2), aligned with other representative type 4 MT mentioned in the text. The sequence labelled GmMT4 refers to soybean MT4, and BQ975039_Ha to sunflower MT4, both reported in [53]. All other sequences are retrieved from UniProt and refer to MT4 homologues from soybean (O22378_SOYBN and O23958_SOYBN), sesame

Although raising awareness of the prevalence and farreaching consequences of (human) zinc deficiency has been a long and slow process [9], zinc deficiency is now recognised as one of the most frequent micronutrient deficiencies [10]. It is estimated that between a sixth and a third of the world's population is at risk of inadequate zinc(II) intake $[11,12]$, especially where diets are largely plant-based [10]. This staggering impact has been recognised by policymakers in the 2008 and 2012 Copenhagen Consensus conferences [13], and has meanwhile fostered practical initiatives and programmes such as HarvestPlus [14]. The latter is aimed at increasing the nutritional value of edible crops through the traditional breeding approaches-in other words, biofortification [15-18]. However, zinc(II) accumulation by plants is not only critical to combat human zinc deficiency, but also for food security in general, because insufficient zinc(II) uptake by plants, which is estimated to occur on $162 \mathrm{MHa}$ of arable land, severely limits crop yields [10]. For these reasons, research into the molecular details of zinc(II) trafficking in plants has intensified throughout the past decade, leading to the identification of scores of membrane-bound zinc(II) transporters [19-22]. Particular focus has been given more recently to zinc(II) trafficking into seeds [23-25], with support from metallomics-type imaging [26] and speciation studies [27].

It has been argued recently that enzyme-bound zinc(II) is now reasonably well understood, but that the nature of "mobile" zinc(II) in biological systems has remained largely mysterious [28]. In particular, and despite major progress in elucidating assembly pathways for many metalloproteins that depend on other essential metals, it is still unclear how the thousands of nascent zinc(II)-requiring proteins actually acquire their metal co-factor. It is now, however, well established that the extremely low concentrations of "free" zinc(II) in cytosols [29] are insufficient to permit this
(Q9FUJ8_SESIN), wheat (EC1_WHEAT and EC3_WHEAT), and barley (I3QM95_HORVU). Cys residues are highlighted in yellow; His residues in cyan. Charged residues are highlighted in red (Asp and Glu), and blue (Lys and Arg). Domain organisation and the residues forming the mononuclear $\mathrm{Cys}_{2} \mathrm{His}_{2}$ site are also indicated

process to occur at reasonable rates, and that ligands with appropriate affinities and fast zinc(II) binding kinetics must play a role. Metallothioneins (MTs)—small, cysteine-rich proteins that bind several metal ions in typical metal-thiolate clusters-have long been proposed as such near-ubiquitous bioligands that fulfil these criteria [30, 31]. A number of in vitro and in vivo studies have demonstrated that MTbound zinc(II) can be transferred to zinc(II)-requiring proteins [32-34].

Flowering plants express up to four different types of MTs [35-37], with the types defined by the number and spacing of Cys residues. After the discovery of MTs in plants in the late 80 s $[38,39]$, relatively little work on the protein level was accomplished, but the past decade has seen a welcome and steady proliferation of biophysical studies on plant MT proteins. Spectroscopic data and information on metal stoichiometry are available for types 1-3 [40-44], but the best-studied plant MT is the type $4 \mathrm{MT} \mathrm{E}_{\mathrm{C}}-\mathrm{I} / \mathrm{II}$ from wheat [45-49].

Type 4 MTs (Fig. 1) are also of particular interest in the context of seed zinc(II) homeostasis: they are almost exclusively expressed in developing seeds, where their expression is highly upregulated during embryogenesis and seed maturation [37, 50, 51], and the proteins are typically isolated with varying amounts of zinc(II) bound from either native or recombinant hosts $[45,46,52,53]$. Wheat $E_{C}$ was isolated from wheat germs in its fully metallated form, with a dominating $\mathrm{Zn}_{6}$ species, but a $\mathrm{M}_{7}$ species that included copper was also observed $[39,45]$. It is unknown whether the copper was incorporated into the protein in planta or during purification. Recombinant expression in E. coli typically yields metal-saturated MTs, although exceptions are known [37].

Furthermore, their heterologous expression in yeast [54] or E. coli [55] and their ectopic expression in plants [55] 
lead to cellular zinc(II) accumulation. Silencing of MT4 genes in A. thaliana led to lower zinc(II) contents in seeds, which was accompanied by growth inhibition that could be rescued by elevated zinc(II) supply. In turn, overexpression of these genes led to larger seeds and more vigorous seedling growth [55]. In contrast to most other MTs, the expression of type 4 plant MTs is not metalloregulated, but is governed by plant hormones [37]. Type 4 MTs are unlikely to play a role in metal toxicity, although some studies have found that they are able to confer zinc(II) or copper tolerance when expressed heterologously [54] or ectopically [56]. The regulation by abscisic acid points towards a role in desiccation and/or rehydration, and it is likely that especially the latter process may require the supply of zinc(II) to newly synthesised proteins. Evidently, a prerequisite of zinc(II) donation during rehydration requires zinc(II) storage before or during desiccation, and it is an attractive proposition that type 4 MTs are important in both of these processes.

The primary sequences of type 4 MTs comprise three Cys-rich stretches with 6, 6, and 5 Cys residues, respectively. These three stretches are separated by relatively short Cys-free regions. In addition, two histidine residues in the second Cys-rich stretch are almost fully conserved in flowering plants [45]. Wheat $\mathrm{E}_{\mathrm{C}} \mathrm{I} / \mathrm{II}$ is the only plant MT for which 3D structures are available [57-59]. All 17 cysteines and the two histidines bind six zinc(II) ions in two separate domains, with all zinc(II) ions having tetrahedral coordination spheres. The six cysteines of the $\mathrm{N}$-terminal $\gamma$-domain (domain I in Fig. 1) form a $\mathrm{Zn}_{2} \mathrm{Cys}_{6}$ binuclear cluster with two bridging thiolates. The remaining 11 cysteines and the 2 histidines in the second domain (domain II, also termed the beta(E) domain [57]) bind a total of four zinc(II) ions. Type 4 MTs are unique amongst MTs in that they contain a mononuclear $\mathrm{Cys}_{2} \mathrm{His}_{2}$ site; in wheat $\mathrm{E}_{\mathrm{C}}$, this is formed by His32, His40, Cys46, and Cys48. ${ }^{1}$ The remaining three zinc(II) ions are bound to nine cysteines; in the published 3D structure, these have been modelled as a six-membered ring consisting of the three zinc(II) ions and three bridging thiolates, with each zinc(II) ion also bound to two terminal thiolates-in analogy to the $\mathrm{M}_{3} \mathrm{Cys}_{9}$ clusters found in mammalian and several other MTs from animals [46, 60]. Correct population of the mononuclear site with a zinc(II) ion is absolutely critical to ensure an ordered structure and defined metal-loading for the entire domain II [61].

Arabidopsis thaliana, a dicotyledonous plant, has two type 4 MT homologues ${ }^{2}$ amongst its seven active MT

\footnotetext{
${ }^{1}$ Note that residue numbering in the literature is not unanimous; the numbering used here is based on the full-length sequence of natively isolated wheat $\mathrm{E}_{\mathrm{C}}-\mathrm{I} / \mathrm{II}$ in which the $\mathrm{N}$-terminal methionine is cleaved, i.e., the first residue is Gly1 [45].

2 In the MT literature, it is common to use the term "isoform" to refer to different MT proteins of a particular organism. However, this is strictly speaking incorrect, as "isoforms" are derived from the
}

genes [62]. MT4a and MT4b contain 83 and 84 amino acid residues, respectively, in their primary protein sequences (Fig. 1). Like their $\mathrm{E}_{\mathrm{C}}$ homolog from wheat, they comprise 17 cysteines and two histidines and bind six zinc(II) ions [37]. It appears that these proteins are particularly important in the early stages of germination and seedling growth, when the young plant has to rely on its internal zinc(II) stores to populate zinc(II)-requiring proteins [55]. Indeed, the mRNA levels for several zinc(II)-requiring transcription factors and enzymes were reduced in A. thaliana plants with co-silenced MT4 genes [55]. Intriguingly, although both homologues are exclusively expressed in developing seeds, reporter assays have revealed that they differ in their temporal and spatial expression patterns: MT4a expression in the plant embryo starts later and remains restricted to vascular tissues, whilst MT4b expression starts earlier, is overall higher and evenly distributed throughout all embryonic cells [55]. This has led to the suggestion that the biological functions of these two closely similar MT4 homologues (84\% sequence identity on the amino acid level) are likely to differ, with MT4a being involved in metal transport and MT4b in metal storagealthough we note that ultimately, all stored zinc(II) will have to be mobilised.

The general concept that biophysical properties of a protein should be correlated with their biological function is also relevant to MTs [61-66]. This is particularly apparent for MTs from organisms where more than one homologue is active, as shown for C. elegans MTL1 and MTL2 [67, 68], mammalian MT1 and MT2 [69], sea urchin SpMTA and SpMTB [70], and snail MTs [71]. Most of the latter studies have focused on metal specificity; the A. thaliana MT4 system offers the opportunity to compare the binding properties for a single metal-zinc(II)—of two closely similar proteins from the same biological system. Combining electrospray ionisation mass spectrometry (ESI-MS) and nuclear magnetic resonance (NMR) spectroscopy, we have studied proton-induced zinc(II) loss to correlate speciation with protein folding. Second, in the light of the suggested different biological functions, and the idea that MTs may directly transfer zinc(II) to other proteins [32-34], we were particularly keen to explore the propensity of MT4a and MT4b to transfer zinc(II), and have used the small-molecule metal chelator EDTA to probe this.

\footnotetext{
Footnote 2 (continued)

same gene, e.g. by alternative splicing. We, therefore, prefer the term "homologue".
} 


\section{Experimental}

\section{Protein expression and purification}

Expression and purification of these two homologues in their unlabelled forms were previously described by our group [36]. In brief, pET-based plasmids containing the coding regions for MT4a and MT4b, kindly provided by Peter Goldsbrough, were used to transform E. coli cells (Rosetta 2(DE3)pLysS; Novagen). Protein expression was induced by $0.5 \mathrm{mM}$ isopropyl- $\beta$-D-1-thiogalactoside (IPTG), and at the same time, the medium was supplemented with $0.5 \mathrm{mM} \mathrm{ZnSO}_{4}$. The cell lysate was fractionated by chemical precipitation using a 100:8 (v/v) ethanol:chloroform mixture [72]. The precipitated protein(s) were redissolved in $20 \mathrm{mM}$ ammonium bicarbonate buffer $(\mathrm{pH} \mathrm{7.8)}$ and purified by gel filtration chromatography (GE Healthcare Superdex G75 16/60 HiLoad column mounted on an ÄKTA Purifier 10). Labelled proteins for NMR spectroscopy were expressed in M9 media containing either ${ }^{15} \mathrm{NH}_{4} \mathrm{Cl}$ or ${ }^{13} \mathrm{C}$-glucose $/{ }^{15} \mathrm{NH}_{4} \mathrm{Cl}$ as sources of ${ }^{15} \mathrm{~N}$ for singly or ${ }^{13} \mathrm{C} /{ }^{15} \mathrm{~N}$ for doubly labelled samples using standard protocols. Labelled protein expression was induced at $\mathrm{OD}_{600}=1.0-1.1$, using $0.5 \mathrm{mM}$ IPTG, with supplementation of $0.5 \mathrm{mM} \mathrm{ZnSO}_{4}$. The cells were allowed to grow for $14 \mathrm{~h}$ at $20^{\circ} \mathrm{C}$ at $180 \mathrm{rpm}$, before harvesting by centrifugation at $5000 \times g$ for $15 \mathrm{~min}$ at $4{ }^{\circ} \mathrm{C}$.

\section{Determination of protein concentration and metal- protein stoichiometry}

Inductively Coupled Plasma-Optical Emission Spectroscopy (ICP-OES) (Perkin-Elmer Optima 5300 DV, Model S10) was used to determine the $\mathrm{S}, \mathrm{Zn}, \mathrm{Cd}$, and $\mathrm{Cu}$ contents of the purified proteins as described previously [73, 74]. In addition, the protein concentration was also routinely determined from the concentration of free thiols (cysteine) in the EDTA-demetallated proteins by Ellman's reagent, 5,5'-dithio-bis(2-nitrobenzoic acid) (DTNB) at $412 \mathrm{~nm}$ by UV-visible spectroscopy using $N$-acetyl-cysteine as standard (Biomate 3 spectrophotometer, Fisher Scientific, UK). Typically, ICP-OES and UV-Vis results agreed within $10 \%$.

\section{UV-visible spectroscopy: Zn transfer to EDTA}

The metal chelator EDTA [Ethylenediaminetetraacetic acid; 2,2',2",2"' -(ethane-1,2-diyldinitrilo)tetraacetic acid; SigmaAldrich, UK] was used to study the metal transfer dynamics of MT4a and MT4b by UV-Vis spectroscopy. Zn ${ }_{6}$ MT4a or $\mathrm{Zn}_{6} \mathrm{MT} 4 \mathrm{~b}(5 \mu \mathrm{M}, 0.7 \mathrm{~mL}, 25 \mathrm{mM}$ Tris buffer, $\mathrm{pH}$ 7.33) was reacted with EDTA at different concentrations (0.05, $0.25,0.5 \mathrm{mM}, 25 \mathrm{mM}$ Tris buffer, $\mathrm{pH} 7.33$ ) at $298 \mathrm{~K}$. Metal release was monitored as a change in absorption at $220 \mathrm{~nm}$. The blank solution contained an equivalent concentration of EDTA in the same reaction buffer. Changes in absorbance were monitored for $3 \mathrm{~h}$. All UV-visible experiments were carried out using a Cary 50 (Varian) spectrophotometer. Data were processed in Microsoft Excel and plotted using Origin Pro 9.1.

\section{Mass spectrometry for observation of metallospecies at different $\mathrm{pH}$ values and during reaction with EDTA}

The proteins were desalted and buffer-exchanged $(10 \mathrm{mM}$ $\mathrm{NH}_{4} \mathrm{HCO}_{3}, \mathrm{pH}$ 7.8) using PD-10 columns (Sephadex G25, GE Healthcare). The protein eluates were concentrated using Amicon Ultra-4 (3000 MWCO, Millipore) filter devices.

To observe speciation at different $\mathrm{pH}$ values, desalted aliquots of $\mathrm{Zn}_{6} \mathrm{MT} 4 \mathrm{a}$ and $\mathrm{Zn}_{6} \mathrm{MT} 4 \mathrm{~b}(25 \mu \mathrm{M}, 200 \mu \mathrm{L}, 10 \mathrm{mM}$ $\mathrm{NH}_{4} \mathrm{HCO}_{3}, \mathrm{pH}$ 7.8) were acidified with small volumes of different concentrations of formic acid (0.1-5 M). Mass spectra of the samples $\left(25 \mu \mathrm{M}, 10 \% \mathrm{v} / \mathrm{v} \mathrm{CH} \mathrm{CH}_{3} \mathrm{OH}, 10 \mathrm{mM}\right.$ $\mathrm{NH}_{4} \mathrm{HCO}_{3}$ buffer, $\mathrm{pH}$ 7.8-2.4) were recorded. To avoid salt contamination from the $\mathrm{KCl}$ solution of the glass electrode (Hamilton Biotrode $\mathrm{pH}$ electrode), each sample was divided into two aliquots and the $\mathrm{pH}$ was measured before (aliquot 1, discarded) and after (remainder of aliquot 2) acquisition of mass spectra. The $\mathrm{pH}$ values given are not corrected for the $10 \% \mathrm{CH}_{3} \mathrm{OH}$ content.

For observation of speciation during reaction with EDTA, desalted solutions of $\mathrm{Zn}_{6} \mathrm{MT} 4 \mathrm{a}$ or $\mathrm{Zn}_{6} \mathrm{MT} 4 \mathrm{~b}(270 \mu \mathrm{M}$, $10 \mathrm{mM} \mathrm{NH}_{4} \mathrm{HCO}_{3}$ buffer, $\mathrm{pH}$ 7.8) were reacted with six molar equivalents of EDTA $\left(1620 \mu \mathrm{M}\right.$ in $10 \mathrm{mM} \mathrm{NH}_{4} \mathrm{HCO}_{3}$; $\mathrm{pH}$ adjusted to 7.8 with $\mathrm{NH}_{3}, 298 \mathrm{~K}$ ) for up to $22 \mathrm{~h}$. At different time intervals, aliquots were taken and diluted $\left(25 \mu \mathrm{M}, 10 \% \mathrm{v} / \mathrm{v} \mathrm{CH}_{3} \mathrm{OH}, 10 \mathrm{mM} \mathrm{NH}_{4} \mathrm{HCO}_{3} \mathrm{pH}\right.$ 7.8) prior to recording mass spectra. The $\mathrm{pH}$ value after the reaction was checked and found to have not changed significantly.

All mass spectra were recorded on a Bruker Daltonics MicroTOF mass spectrometer fitted with an electrospray ionisation source operating in positive mode. The samples were injected into the spectrometer by a syringe pump with a flow rate of $240 \mu \mathrm{L} \mathrm{h}^{-1}$. Other parameters were fixed as: temperature $195{ }^{\circ} \mathrm{C}$, nebulizer 0.6 bar, dry gas $4.5 \mathrm{~L} \mathrm{~min}^{-1}$, capillary exit $100 \mathrm{~V}$, skimmer $150 \mathrm{~V}$, skimmer2 $25.2 \mathrm{~V}$, hexapole1 $24.2 \mathrm{~V}$, hexapole2 $22.4 \mathrm{~V}$, hexapole RF $450 \mathrm{~V}$, transfer time $81 \mu \mathrm{s}$, and detector TOF $2300 \mathrm{~V}$. The data were recorded over $0.4-2 \mathrm{~min}$ for a range of $500-5000 \mathrm{~m} / \mathrm{z}$. The experimental data were then smoothed and deconvoluted using Bruker Compass DataAnalysis v. 4 (Bruker Daltonik, Germany). 


\section{Nuclear magnetic resonance (NMR) spectroscopy}

\section{Sample conditions, NMR data acquisition, and processing}

All protein samples (various concentrations) were prepared in a standard buffer, in the following referred to as "NMR buffer" (50 mM Tris- $\mathrm{D}_{11}, 10 \% \mathrm{D}_{2} \mathrm{O}, 50 \mathrm{mM} \mathrm{NaCl}$ ) at different $\mathrm{pH}$ values (vide infra). Homonuclear ${ }^{1} \mathrm{H}$ spectra were acquired on unlabelled samples for $\mathrm{Zn}_{6} \mathrm{MT} 4 \mathrm{a}$ and $\mathrm{Zn}_{6} \mathrm{MT} 4 \mathrm{~b}$. Heteronuclear 2D and 3D $\left[{ }^{1} \mathrm{H},{ }^{15} \mathrm{~N}\right]$ spectra were obtained for ${ }^{15} \mathrm{~N}$-labelled samples for $\mathrm{Zn}_{6} \mathrm{MT} 4 \mathrm{a}$ and $\mathrm{Zn}_{6} \mathrm{MT} 4 \mathrm{~b}$, and a ${ }^{13} \mathrm{C}$ - and ${ }^{15} \mathrm{~N}$-labelled sample of $\mathrm{Zn}_{6} \mathrm{MT} 4 \mathrm{~b}$ was used to record triple-resonance data ( $\mathrm{HNCA}$ and $\mathrm{HN}(\mathrm{CO}) \mathrm{CA})$ to facilitate sequential assignment.

Experiments were carried out using a Bruker Avance 700 Ultrashield spectrometer mounted with a TCI cryoprobe. Spectra were recorded at an operating frequency of $700.24 \mathrm{MHz}$ for ${ }^{1} \mathrm{H}, 70.95 \mathrm{MHz}$ for ${ }^{15} \mathrm{~N}$, and $176.08 \mathrm{MHz}$ for ${ }^{13} \mathrm{C}$. The residual water resonance was used as a reference for ${ }^{1} \mathrm{H}$ chemical shifts; ${ }^{13} \mathrm{C}$ and ${ }^{15} \mathrm{~N}$ are referenced externally to DSS (2,2'-dimethyl-2-silapentane-5-sulfonate) and ${ }^{15} \mathrm{NH}_{4} \mathrm{Cl}$, respectively. All NMR spectra were acquired at $298 \mathrm{~K}$. Recorded spectra were processed using Bruker Topspin v. 2.1 software. For 2D and 3D spectra, phase- and baseline-corrected Topspin files were transferred to Sparky v. 3.106 [75] for analysis.

1D ${ }^{1} \mathrm{H}-\mathrm{NMR}$ spectra were recorded with $16 \mathrm{k}$ complex data points, 128 scans and a spectral width of $15.9 \mathrm{ppm}$. $2 \mathrm{D}\left[{ }^{1} \mathrm{H},{ }^{1} \mathrm{H}\right]$ Total Correlation (TOCSY, mixing time of 60-65 ms) and Nuclear Overhauser Enhancement (NOESY, mixing time of 60 or $100 \mathrm{~ms}$ ) spectra were recorded with 16 scans, 4k data points in F2 and 512 or 400 increments in F1 with a spectral width of 16 ppm centred at the water peak at $\sim 4.7 \mathrm{ppm}$. A squared sine-bell function was used to apodize the raw data prior to Fourier transformation with $2 \mathrm{k} \times 2 \mathrm{k}$ data points. $2 \mathrm{D}$ heteronuclear single quantum coherence $\left[{ }^{1} \mathrm{H},{ }^{15} \mathrm{~N}\right]$ HSQC spectra for $\mathrm{Zn}_{6} \mathrm{MT} 4 \mathrm{a}$ and $\mathrm{Zn}_{6} \mathrm{MT} 4 \mathrm{~b}$ used for assignment purposes were recorded with $4 \mathrm{k}$ data points in F2 $\left({ }^{1} \mathrm{H}\right)$ and 128 increments in $\mathrm{F} 1\left({ }^{15} \mathrm{~N}\right)$. Spectra were acquired with a spectral width of 16 ppm in F2 and 40 ppm in F1 over 16 scans with a ${ }^{1} J_{\mathrm{NH}}$ coupling constant of $90 \mathrm{~Hz}$. The raw data were apodized using a squared sine-bell function and Fourier transformed into $4 \mathrm{k} \times 512$ data points in the $\mathrm{F} 2 \times \mathrm{F} 1$ dimensions, respectively.

$3 \mathrm{D}\left[{ }^{1} \mathrm{H},{ }^{1} \mathrm{H},{ }^{15} \mathrm{~N}\right]$ TOCSY-HSQC (mixing time of $60 \mathrm{~ms}$ ) and NOESY-HSQC (mixing time of $100 \mathrm{~ms}$ ) spectra were acquired with spectral widths of $14 \mathrm{ppm}$ for $\mathrm{F} 3\left({ }^{1} \mathrm{H}\right), 32 \mathrm{ppm}$ for F2 $\left({ }^{15} \mathrm{~N}\right)$ and $14 \mathrm{ppm}$ for F1 $\left({ }^{1} \mathrm{H}\right)$ with 16 scans. Spectra were acquired with 2048 data points in $\mathrm{F} 3\left({ }^{1} \mathrm{H}\right), 36$ increments for $\mathrm{F} 2\left({ }^{15} \mathrm{~N}\right)$, and 128 increments for $\mathrm{F} 1\left({ }^{1} \mathrm{H}\right)$. HNCA and HN(CO)CA spectra were obtained with 2048 data points in $\mathrm{F} 3\left({ }^{1} \mathrm{H}\right), 40$ increments for $\mathrm{F} 2\left({ }^{15} \mathrm{~N}\right)$, and 64 increments for F1 $\left({ }^{13} \mathrm{C}\right)$ with 16 scans. Spectral widths were
14.0 ppm for $\mathrm{F} 3\left({ }^{1} \mathrm{H}\right)$, and $32 \mathrm{ppm}$ for both $\mathrm{F} 2\left({ }^{15} \mathrm{~N}\right)$ and $\mathrm{F} 1$ $\left({ }^{13} \mathrm{C}\right)$. The data were apodized and Fourier transformed into $2 \mathrm{k}(\mathrm{F} 3) \times 64(\mathrm{~F} 2) \times 512(\mathrm{~F} 1)$ data points for $\left[{ }^{1} \mathrm{H},{ }^{1} \mathrm{H},{ }^{15} \mathrm{~N}\right]$ TOCSY-HSQC and $2 \mathrm{k}(\mathrm{F} 3) \times 64(\mathrm{~F} 2) \times 256(\mathrm{~F} 1)$ data points for $\left[{ }^{1} \mathrm{H},{ }^{1} \mathrm{H},{ }^{15} \mathrm{~N}\right]$ NOESY-HSQC, HNCA and HN(CO)CA.

\section{D ${ }^{1} \mathrm{H}$ NMR spectroscopy: $\mathrm{pH}$ dependence and reactions with EDTA}

For experiments to study the $\mathrm{pH}$ dependence of protein folding, the $\mathrm{pH}$ of $\mathrm{Zn}_{6} \mathrm{MT} 4 \mathrm{a}$ or $\mathrm{Zn}_{6} \mathrm{MT} 4 \mathrm{~b}$ samples $(400 \mu \mathrm{M}$, NMR buffer, $\mathrm{pH}$ 8.48) was adjusted with incremental additions of acid (0.1-1 M HCl). Samples were allowed to equilibrate for ca. $10 \mathrm{~min}$ prior to recording $1 \mathrm{D}^{1} \mathrm{H}-\mathrm{NMR}$ spectra. Trimethylsilyl propionate (TSP) was used as an internal standard. In each case, the $\mathrm{pH}$ was measured before and after NMR data acquisition. To allow rapid monitoring of protein folding during reaction with EDTA, $\mathrm{Zn}_{6} \mathrm{MT} 4 \mathrm{a}$ or $\mathrm{Zn}_{6} \mathrm{MT} 4 \mathrm{~b}$ (277 $\mu \mathrm{M}, \mathrm{NMR}$ buffer, pH 7.4) was mixed with an equimolar amount of EDTA [1:6 with respect to (protein), NMR buffer, $\mathrm{pH}$ 7.4]. Immediately after mixing a series of $1 \mathrm{D},{ }^{1} \mathrm{H}-\mathrm{NMR}$ spectra were recorded. The $\mathrm{pH}$ value after the reaction was checked and found to have not changed significantly.

\section{$\left[{ }^{1} \mathrm{H},{ }^{15} \mathrm{~N}\right] \mathrm{HSQC}$ NMR spectroscopy: reaction with EDTA}

Homogeneously labelled $\left({ }^{15} \mathrm{~N}\right)$ samples of $\mathrm{Zn}_{6} \mathrm{MT} 4 \mathrm{a}$ or $\mathrm{Zn}_{6} \mathrm{MT} 4 \mathrm{~b}$ (251 and $267 \mu \mathrm{M}$, NMR buffer, $\mathrm{pH}$ 7.43) were mixed with EDTA (1:6 with respect to [protein], NMR buffer, pH 7.4, $298 \mathrm{~K}$ ). Immediately after mixing, a series of $2 \mathrm{D}\left[{ }^{1} \mathrm{H},{ }^{15} \mathrm{~N}\right] \mathrm{HSQC}$ spectra $(4 \mathrm{k} \times 64$ datapoints over 4 scans; $320 \mathrm{~s}$ total duration per experiment) were recorded. The $\mathrm{pH}$ value after the reaction was checked and found to have not changed significantly.

\section{Homology models and electrostatic potentials}

Structural models were generated using Modeller v. 9.13 [76]. The solution structures of the separate domains of zinc(II)-loaded wheat $\mathrm{E}_{\mathrm{C}}$ (PDB 2L62 [58] and 2KAK [57]) were used as templates. Side-chain conformations of MoDELLER-generated models were optimised using the program ScwRL v. 4.0 [77]; however, side-chain conformations of metal coordinated residues (Cys and His) were kept as obtained from the MoDELLER runs. Finally, $\mathrm{Zn}$ ions were manually incorporated into the Scwrl4 optimised model, and structures were energy-minimised using the AMBER ffSB14 force field incorporated in the program CHIMERA v. 1.11. Generated models were validated using the WHATIF server [78]. Electrostatic surface potentials were calculated using the APBS (Adaptive Poisson-Boltzmann solver) plugin of PyMol v. 1.8, with the underlying partial charges calculated using PDB2PQR v. 2.0.0 [79]. 

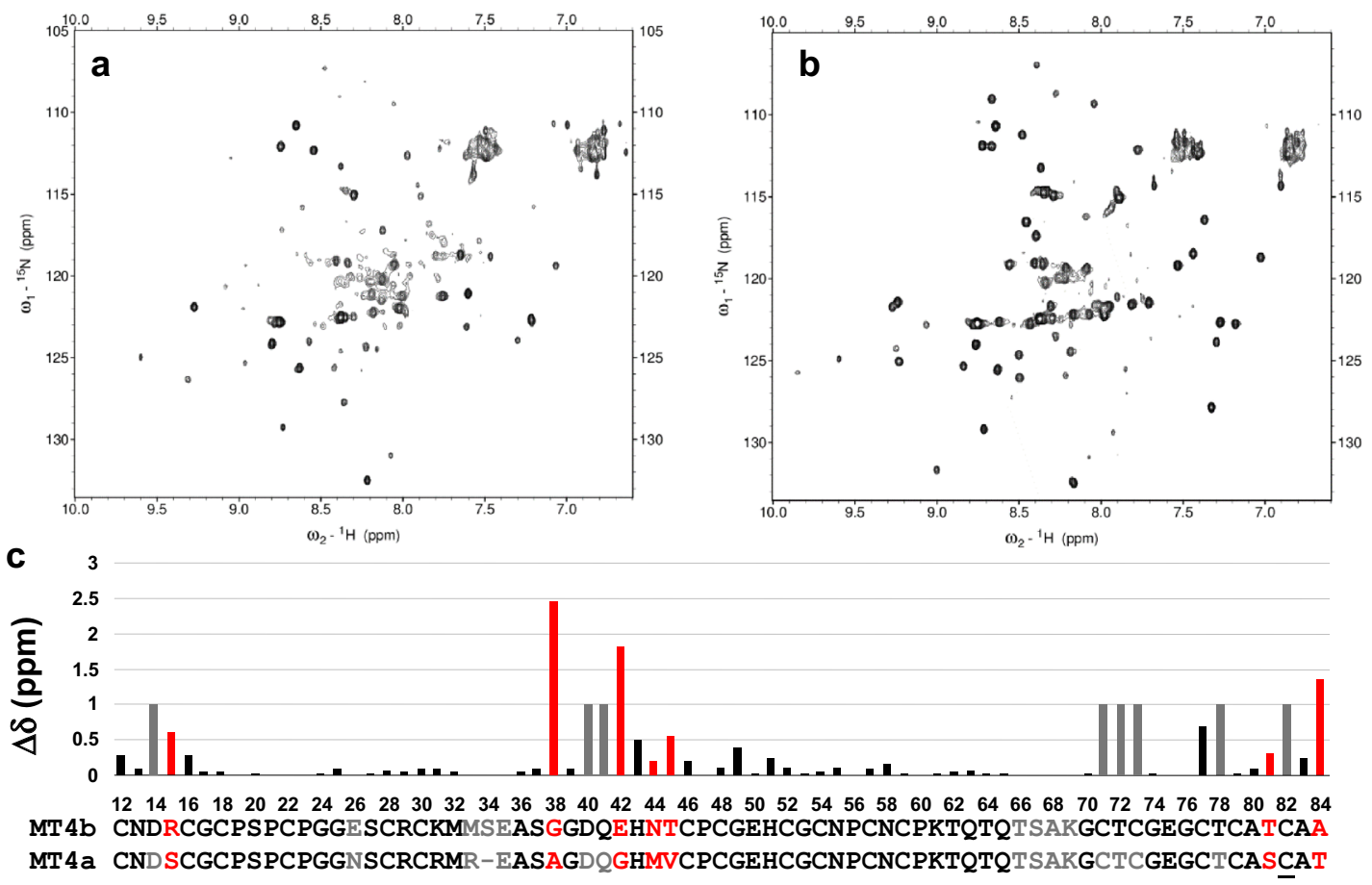

Fig. 2 Protein folding, chemical shift assignment, and comparison of $A$. thaliana MT4a and MT4b. a $2 \mathrm{D}\left[{ }^{15} \mathrm{~N},{ }^{1} \mathrm{H}\right] \mathrm{HSQC}$ spectrum of $\mathrm{Zn}_{6} \mathrm{MT} 4 \mathrm{a}, \mathbf{b} 2 \mathrm{D}\left[{ }^{15} \mathrm{~N},{ }^{1} \mathrm{H}\right]$ HSQC spectrum of $\mathrm{Zn}_{6} \mathrm{MT} 4 \mathrm{~b} \mathbf{c}$ Weighted differences $\left(\Delta \delta=\left(\Delta \delta\left({ }^{1} \mathrm{H}\right)^{2}+\left(1 / 7 \times \Delta \delta\left({ }^{15} \mathrm{~N}\right)\right)^{2}\right)^{1 / 2}\right.$ between backbone $\mathrm{N}-\mathrm{H}$ chemical shifts between MT4a (residues 12-83) and MT4b (residues 12-84). The sequences of MT4a and MT4b, as well as the

\section{Results and discussion}

We have previously expressed and purified the MT4a and MT4b proteins from A. thaliana [37]. The determination of the masses of the apo proteins by ESI-MS confirmed cleavage of the $\mathrm{N}$-terminal initiator methionine residue. ESIMS at neutral $\mathrm{pH}$ and inductively coupled plasma-optical emission spectroscopy (ICP-OES) also confirmed that our expression and purification protocols yield overwhelmingly the $\mathrm{Zn}_{6}$ species in both cases; this was confirmed for each individual batch used in the studies described below.

\section{Sequential assignment of $A$. thaliana MT4a and MT4b}

To enable comparisons between the two MT homologues on a structural level, sequential NMR assignments were obtained for both $\mathrm{Zn}_{6} \mathrm{MT} 4 \mathrm{a}$ and $\mathrm{Zn}_{6} \mathrm{MT} 4 \mathrm{~b}$ (see Supplementary Table $\mathrm{S} 1$ for chemical shift lists). Most residues lying within the two domains were assigned for both proteins (Fig. 2); this indicates that both domains of both proteins were reasonably well folded-with some exceptions that will be discussed later on. The $11 \mathrm{~N}$-terminal residues (Fig. 1) could not be assigned for either protein. Extended N-termini corresponding bars in the chart are colour-coded to highlight nonassigned residues (grey; in cases where assignments were only possible in one homologue, an arbitrary value of $\Delta \delta=1$ was allocated to highlight this difference) and residues that differ between the two proteins (red) (also see "Discussion"). Cys81 (underlined) in MT4a was only observed in $2 \mathrm{D}{ }^{1} \mathrm{H}$ spectra

are a feature of some type 4 MTs from dicotyledonous plants [36]. Our inability to assign these residues for either MT4a or MT4b suggests that these stretches are largely unstructured and flexible. Indeed, given that the structure of wheat $\mathrm{E}_{\mathrm{C}}$ domain I (also termed the $\gamma$ domain) is known [58], it is evident that the $\mathrm{N}$-terminal extension of certain dicot MT4s is unlikely to be required for protein folding. Other residues that are missing in our assignments are two (MT4a) or three (MT4b) residues in the region that links the two domains, and four residues in the Cys-free loop within domain II, in each case indicating high structural flexibility. Several further residues in domain II of MT4a were also not assignable, including Cys 70 and Cys81 (see Supplementary Table S1 for details). The NMR assignments will be used in the following to rationalise the effects of proton- and chelator-induced metal loss on protein folding.

\section{Proton-induced metal loss: ESI-MS and NMR studies}

An important property that is often used to distinguish MTs from other metal-binding proteins is the comparatively low $\mathrm{pH}$ at which their bound metal ions succumb to displacement by protons $[40,80]$. We have previously determined the $\mathrm{pH}$ of half displacement [pH(1/2)] of A. thaliana MT4a (4.55) 
Fig. 3 Representative deconvoluted mass spectra at different $\mathrm{pH}$ values $(25 \mu \mathrm{M}$ protein, $10 \mathrm{mM} \mathrm{NH}_{4} \mathrm{HCO}_{3}, 10 \%$ $\mathrm{MeOH})$. The neutral masses of 8539.2 (theoretical mass 8539.07 ) and 8685.5 (theoretical mass 8686.07) correspond to full-length MT4a or MT4b (without $\mathrm{N}$-terminal Met), respectively, with $6 \mathrm{Zn}^{2+}$ ions bound

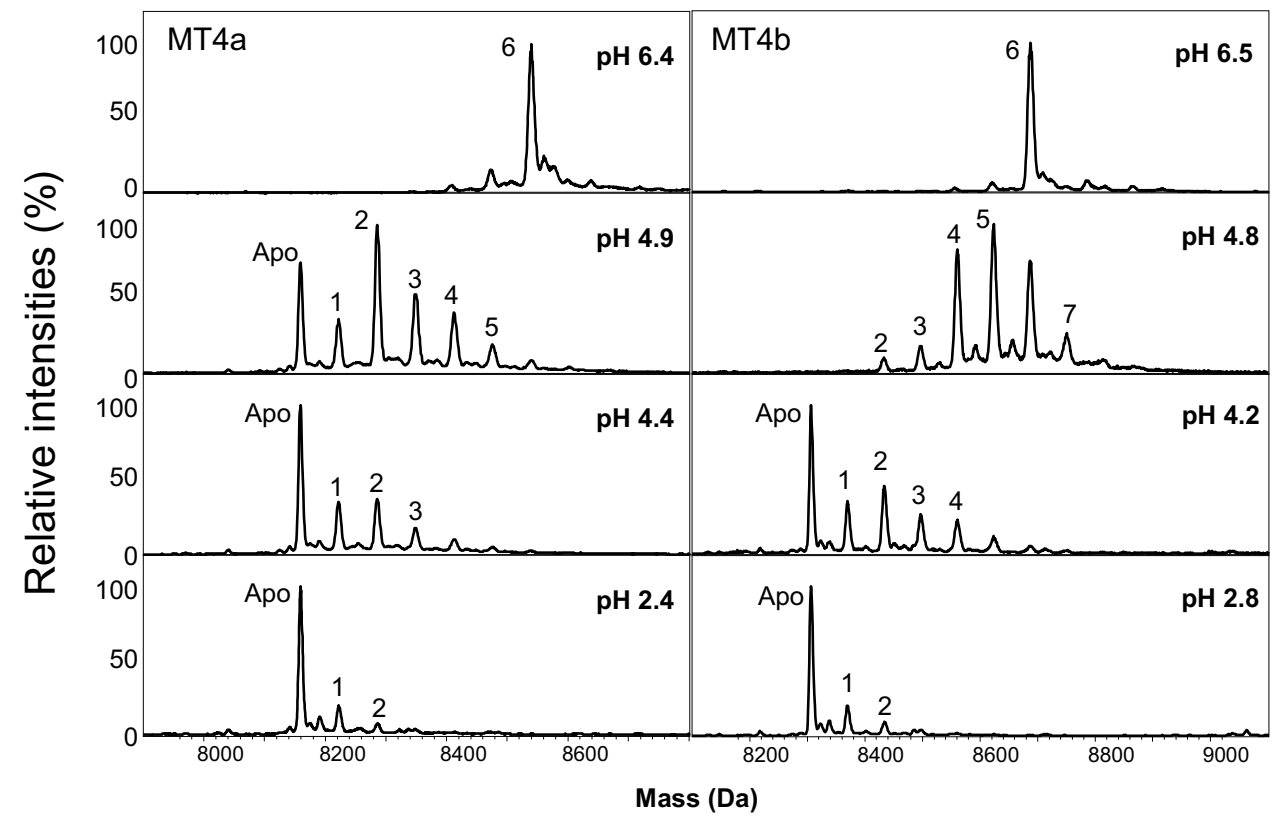

and MT4b (4.56) by UV-Vis spectroscopy, finding that by this measure, their overall $\mathrm{pH}$ stability was essentially the same [36], and also did not differ significantly from that of wheat $\mathrm{E}_{\mathrm{C}}$ determined under the same conditions (4.53 [81]).

The determination of $\mathrm{pH}(1 / 2)$ values is a quick but relatively coarse measure to characterise MTs; more insight may be gained by ESI-MS, which is the only method capable of providing information on which species are present under the given conditions [82-87]. ESI-MS spectra of $\mathrm{Zn}_{6} \mathrm{MT} 4 \mathrm{a}$ and $\mathrm{Zn}_{6} \mathrm{MT} 4 \mathrm{~b}$ at different $\mathrm{pH}$ values (Fig. 3) confirm that at a $\mathrm{pH}$ well above the $\mathrm{pH}(1 / 2)$, both homologues show a clearly dominating $\mathrm{Zn}_{6}$, i.e., the fully metallated species.

Intriguing differences were captured at $\mathrm{pH}$ values close to the $\mathrm{pH}(1 / 2)$ : whilst the spectrum for MT4b at $\mathrm{pH} 4.8$ was dominated by $\mathrm{Zn}_{5}, \mathrm{Zn}_{4}$, and $\mathrm{Zn}_{6}$ species, the most abundant species for MT4a at $\mathrm{pH} 4.9$ was $\mathrm{Zn}_{2}$ followed by the apo form. No apo form was observed at $\mathrm{pH} 4.8$ for MT4b, but surprisingly, a new over-metalled $\mathrm{Zn}_{7}$ species emerged. Over-metallated species have been observed previously for a range of MTs, including human MT1A [60, 88, 89] and MT3 [90, 91], and wheat $\mathrm{E}_{\mathrm{C}}$ [57]. In each of these cases, the over-metallated species were observed after addition of excess metal. Metal redistribution upon a change in $\mathrm{pH}$ similar to that observed here was also evident for $\mathrm{Cd}$-loaded earthworm MT2 [64], where the over-metalled $\mathrm{Cd}_{8}$ species emerged at $\mathrm{pH} 3.5$, alongside several under-metallated species. The significance of these species is unclear.

Further lowering the $\mathrm{pH}$ to 4.4 for MT4a resulted in formation of apo-MT4a as dominating species, along with under-metallated species of $\mathrm{Zn}_{1}, \mathrm{Zn}_{2}, \mathrm{Zn}_{3}$, and a very low abundance $\mathrm{Zn}_{4}$ species. The spectrum for MT4b at $\mathrm{pH} 4.2$ is broadly similar to that of MT4a at $\mathrm{pH} 4.4$, although $\mathrm{Zn}_{4}$ and
$\mathrm{Zn}_{5}$ species were still more prominent for MT4b. Finally, at even lower $\mathrm{pH}(<3.5)$, the apo forms were the major species for both proteins, but in both cases, $\mathrm{Zn}_{1}$ and $\mathrm{Zn}_{2}$ species were still observed, albeit at low abundances.

In summary, both MTs produced a range of under-metallated species during a $\mathrm{pH}$ titration, but at $\mathrm{pH}$ values around the $\mathrm{pH}(1 / 2)$, MT4b displayed a higher degree of metallation, even though in both examples shown in Fig. 3, the pH of the MT4b solutions was slightly lower than those of the corresponding MT4a solutions.

Subsequently, 1D ${ }^{1} \mathrm{H}$ NMR spectroscopy was employed to investigate the consequences of proton-induced zinc(II) loss on protein folding. As expected for MTs [80], the apo proteins present at $\mathrm{pH} 2.5$ are essentially unfolded, as judged [92] by the complete loss of chemical shift dispersion (Supplementary Fig. S1). Figure 4 focuses on the low-field region which at neutral $\mathrm{pH}$ harbours relatively well-resolved backbone NH resonances from both domains. These ${ }^{1} \mathrm{H}$ NMR data confirm that the most significant changes occur between pH 5 and 4, as was also observed by UV spectroscopy [36] and ESI-MS (Fig. 3), thus demonstrating that metal loss (UV and ESI-MS) and protein unfolding (NMR) are correlated. Most importantly, the data suggest that for both proteins, the two domains have different $\mathrm{pH}$ stabilities. Proton-driven demetallation first leads to unfolding of domain II, followed by unfolding of domain I at lower $\mathrm{pH}$-for example, the MT4a domain I Asn13 resonance shows nearly undiminished intensity at $\mathrm{pH} 4.8$, whilst the various domain II resonances (Met43, His50, Asn57, Gly58, and Ala79) are greatly reduced in intensity. The situation for MT4b is similar, with the resonances for Asn58 and Ala80 being left just about discernible at the somewhat lower $\mathrm{pH}$ of 4.6. At $\mathrm{pH} 4.2$, domain 


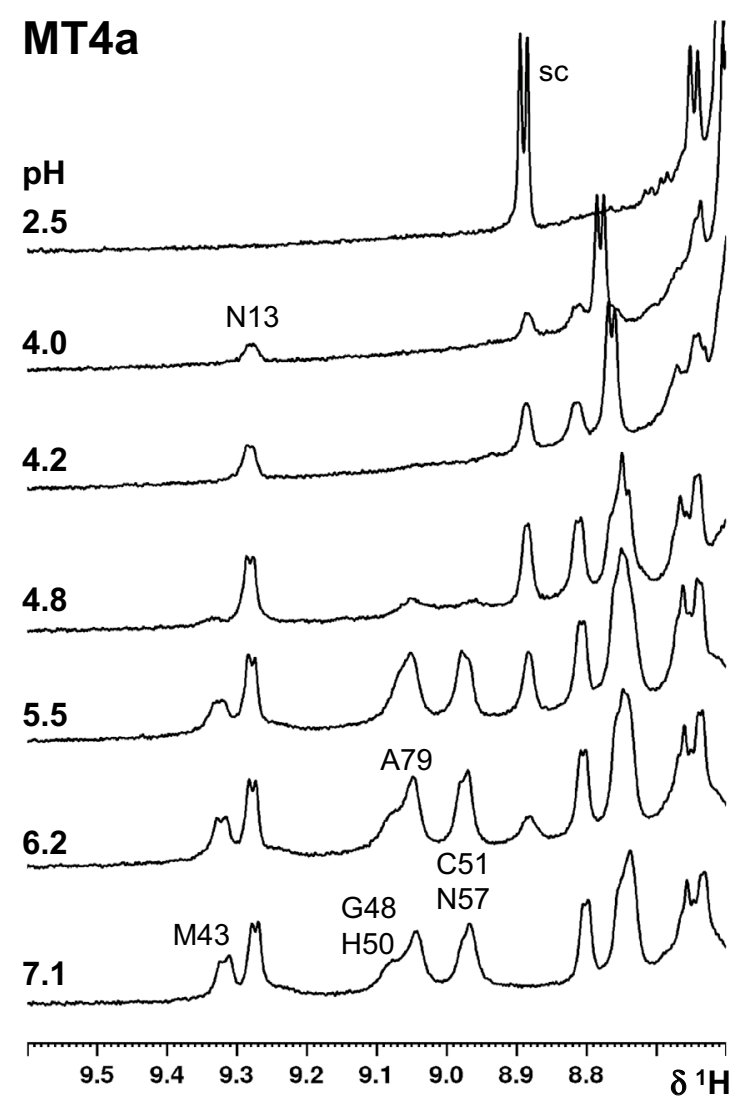

Fig. 4 Low-field region of selected NMR spectra of MT4a and MT4b at different $\mathrm{pH}$ values $\left(400 \mu \mathrm{M}\right.$ protein, $50 \mathrm{mM}$ Tris- $\mathrm{D}_{11}, 10 \% \mathrm{D}_{2} \mathrm{O}$, $50 \mathrm{mM} \mathrm{NaCl}, 298 \mathrm{~K}$ ). The backbone amide proton resonances for

II resonances have disappeared for both proteins, whilst the Asn13 resonance from domain I has reduced in intensity, but is still clearly present. The ${ }^{1} \mathrm{H}$ NMR data do not allow discerning any differences between different sections within the domains for either protein, nor were any obvious differences in the behaviour of the two proteins evident. It is hence not possible to correlate the differences in speciation seen by ESI-MS with differences in protein folding. Most importantly, however, combining the ${ }^{1} \mathrm{H}$ NMR with the ESI-MS data allows inferring that the most $\mathrm{pH}$-labile zinc(II) ions in both homologues reside in domain II.

\section{Reaction with EDTA: UV-visible spectroscopy}

Inspired by suggestions that type 4 MTs may function as zinc(II) donors to nascent $\mathrm{Zn}$-requiring proteins during or after germination [39, 55], we studied the zinc(II) transfer kinetics of the two A. thaliana MT homologues to the metal chelator EDTA, a commonly used probe to study the lability of MT-bound metals [80, 93-97].

Zinc transfer to EDTA under pseudo-first-order conditions (100-fold molar excess) was monitored as a decrease

\section{MT4b}

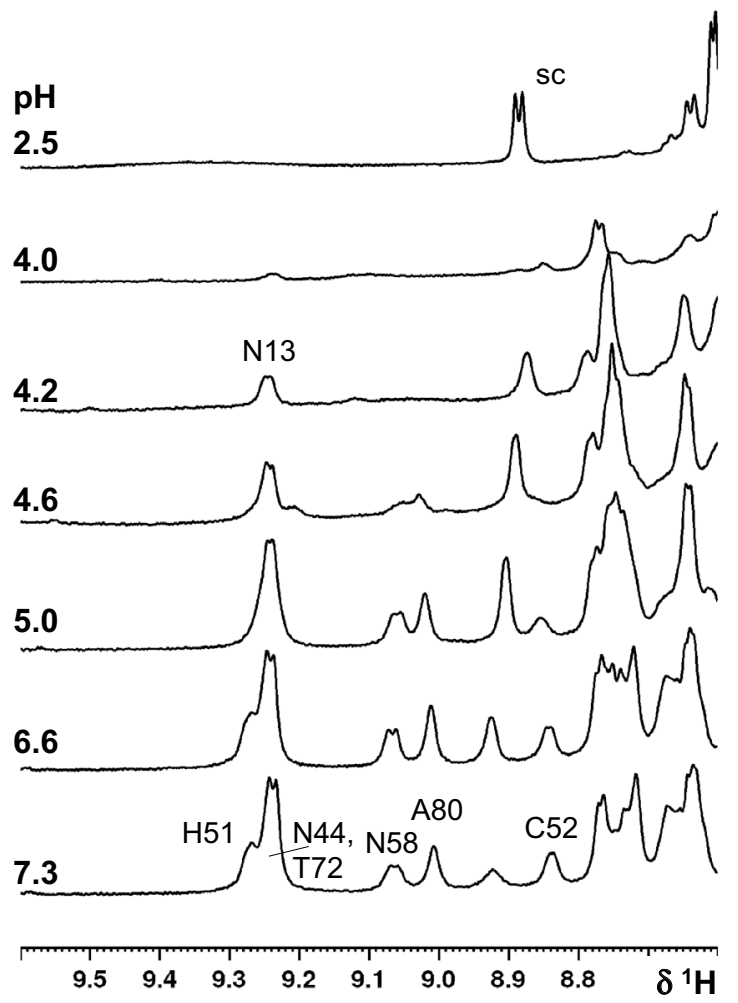

representative residues are annotated. For both proteins, domain II residues are affected at higher $\mathrm{pH}$ values than those of domain I

in absorbance of $\mathrm{Zn}-\mathrm{S}$ bonds at $220 \mathrm{~nm}$ using UV-visible spectroscopy. Although Tris-Cl does not buffer well at $\mathrm{pH}$ 7.3 , this buffer system was chosen for both UV-Vis and NMR studies, as many related studies on MTs had also been carried out in Tris buffer, e.g., [95-97]. The pseudo-firstorder plots in Fig. 5 show that MT4a initially transferred zinc(II) faster than MT4b. Under these conditions, only one phase was observed for MT4b, whilst MT4a displayed biphasic kinetics. The pseudo-first-order rate constant for MT4b was $k_{\mathrm{obs}}=2.8 \times 10^{-4} \mathrm{~s}^{-1}$. The faster step for MT4a proceeded with $k_{\text {obs }}=7.5 \times 10^{-4} \mathrm{~s}^{-1}$; the slower step with $k_{\text {obs }}=9.3 \times 10^{-5} \mathrm{~s}^{-1}$. Hence, the initial metal release from MT4a was almost three times faster than for MT4b under these conditions. MT4a also reacted faster than MT4b when lower EDTA:protein ratios were employed, with clearly decreased reaction rates for either protein (Supplementary Fig. S2). Importantly, the latter fact indicates that the reaction rate depends on the EDTA concentration, i.e., the ratedetermining step is (at least) bimolecular and involves direct interaction between the protein and the chelator. Thus, the two type 4 MTs behave in a broadly similar way to MTs that have been studied by this method $[93,95,96]$, but with some 


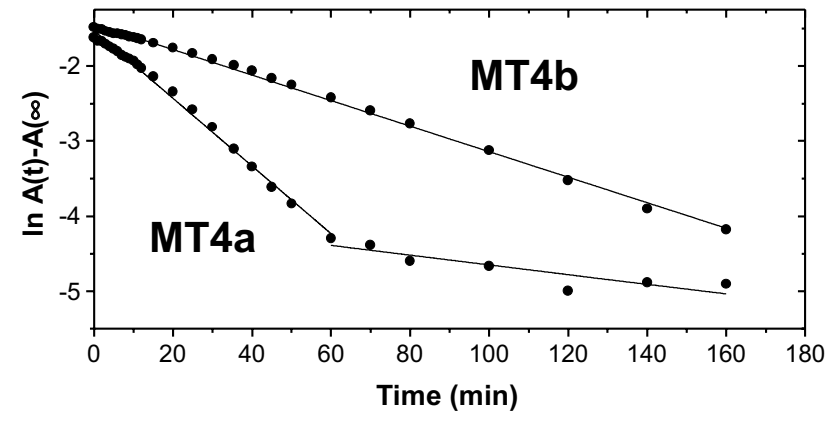

Fig. 5 Semi-logarithmic plot of the reaction of $\mathrm{Zn}_{6} \mathrm{MT} 4 \mathrm{a}$ and $\mathrm{Zn}_{6}$ MT4b with a 100 -fold excess of EDTA at $\mathrm{pH} 7.4$ (5 $\mu \mathrm{M}$ protein, $25 \mathrm{mM}$ Tris buffer, $\mathrm{pH} 7.33,298 \mathrm{~K}$ ). The lines correspond to linear fits, from which rate constants $\left(k_{\text {obs }}\right)$ for pseudo-first-order reaction kinetics were derived

subtle differences to wheat $E_{C}[93]$ as well as to each other. The significance of the observations from UV spectrophotometry will be further discussed once MS and NMR results have been introduced.

\section{Reaction with EDTA: native ESI-MS and NMR spectroscopy}

Native ESI-MS has been used previously to monitor the speciation of MTs during their interactions with other metal acceptors including proteins [93, 96-101]. Here, we have combined this technique with $2 \mathrm{D}\left[{ }^{1} \mathrm{H},{ }^{15} \mathrm{~N}\right]$ HSQC NMR spectroscopy to correlate the folding state of individual domains in different metalloforms. By necessity, the reaction conditions differ from those employed for UV spectrophotometry, because NMR spectroscopy requires higher protein concentrations. Hence, all MS and NMR timecourse experiments were carried out with $250-280 \mu \mathrm{M}$ solutions of proteins, but only equimolar amounts of EDTA with respect to $\left[\mathrm{Zn}^{2+}\right]$, to bring the reaction times within a manageable range (Figs. 6, 7). We also note that different buffer conditions and ionic strengths were used for ESI-MS and NMR experiments; therefore, reaction times for these two experiments cannot be directly compared. Broadly speaking, it appears that the reactions under ESI-MS conditions $(10 \mathrm{mM}$ $\mathrm{NH}_{4} \mathrm{HCO}_{3} \mathrm{pH} 7.8, I=10 \mathrm{mM}$ ) proceeded more slowly than
Fig. 6 Representative deconvoluted mass spectra taken at different time points during the reaction of $\mathrm{Zn}_{6} \mathrm{MT} 4 \mathrm{a}$ or $\mathrm{Zn}_{6} \mathrm{MT} 4 \mathrm{~b}(270 \mu \mathrm{M}$ protein, $10 \mathrm{mM} \mathrm{NH}_{4} \mathrm{HCO}_{3}$ buffer, $\mathrm{pH}$ $7.8,298 \mathrm{~K}$ ) with equimolar EDTA (1.62 mM). Data were acquired on diluted aliquots $\left(25 \mu \mathrm{M}, 10 \%\right.$ v/v $\mathrm{CH}_{3} \mathrm{OH}$, $10 \mathrm{mM} \mathrm{NH}_{4} \mathrm{HCO}_{3} \mathrm{pH} 7.8$ )
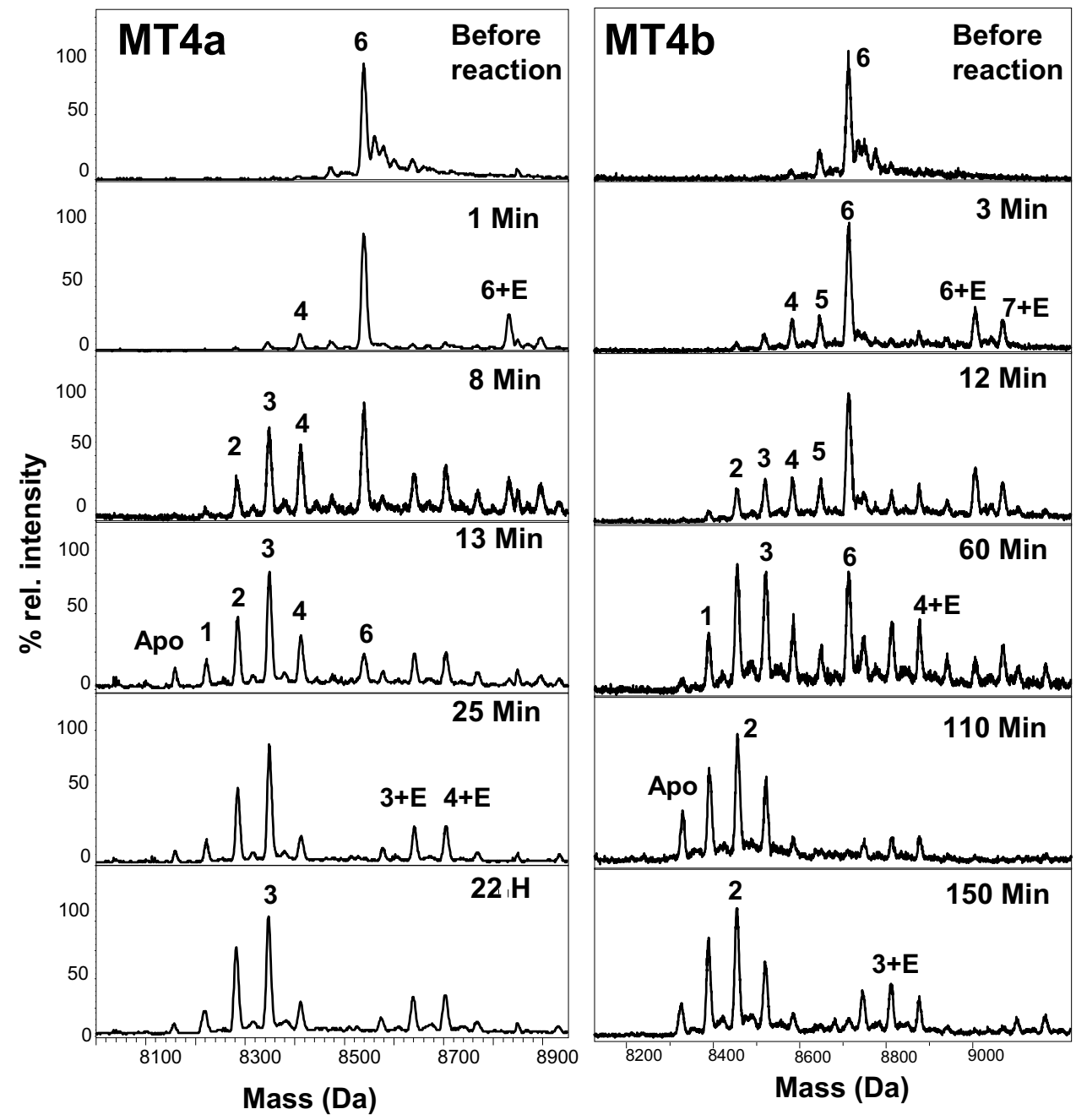

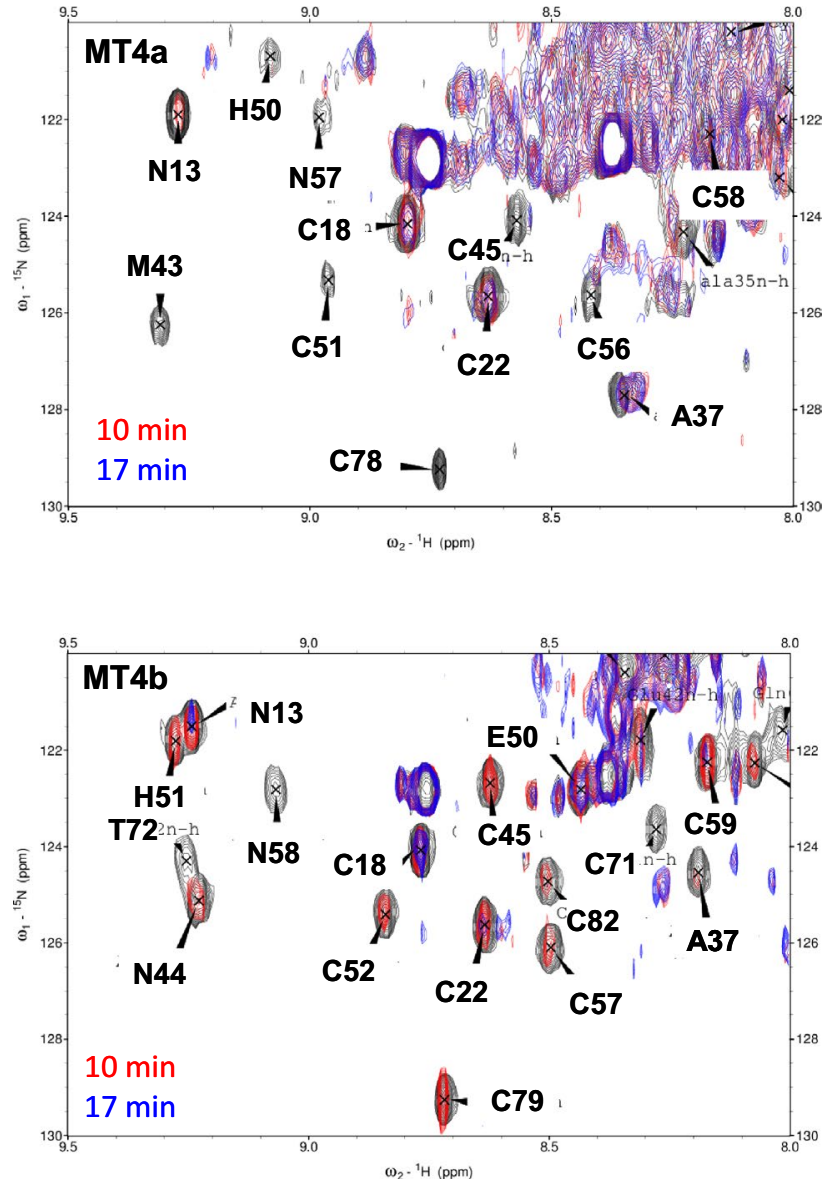

Fig. 7 Representative section of overlaid $2 \mathrm{D}\left[{ }^{1} \mathrm{H},{ }^{15} \mathrm{~N}\right]$ HSQC spectra during the reaction of ${ }^{15} \mathrm{~N}$-labelled $\mathrm{Zn}_{6} \mathrm{MT} 4 \mathrm{a}(251 \mu \mathrm{M})$ or $\mathrm{Zn}_{6} \mathrm{MT} 4 \mathrm{~b}$ $(267 \mu \mathrm{M})$ with equimolar (with respect to [Zn]) EDTA (50 mM Tris$\left.\mathrm{D}_{11}, 50 \mathrm{mM} \mathrm{NaCl}, 10 \% \mathrm{D}_{2} \mathrm{O}, \mathrm{pH} 7.4,298 \mathrm{~K}\right)$. Spectra before the reaction are shown in black, spectra after $10 \mathrm{~min}$ in red, and spectra after $17 \mathrm{~min}$ in blue. The immediate disappearance of domain II resonances for MT4a is evident, whilst domain I resonances persist for both proteins during the first $17 \mathrm{~min}$, albeit at weakened intensities. The very strong persistent peaks are due to a contaminating peptide in both cases

those observed by NMR (50 mM Tris, $50 \mathrm{mM} \mathrm{NaCl}, \mathrm{pH}$ $7.4, I=54 \mathrm{mM})$.

Mass spectra (Fig. 6) recorded immediately after mixing reveal the formation of EDTA adducts for both proteins, in accordance with the conclusion from UV-Vis spectroscopy, i.e., that the reaction requires formation of a complex between protein and chelator. Interestingly, such complexes were even present at the end of the reaction, where they were observed for several under-metallated species. EDTA adducts formation has been previously observed for bacterial SmtA [96] and wheat $E_{C}$ [93], and also has been postulated to occur during reaction with mammalian MTs [95]. In addition, the requirement for direct interaction between MT and recipient proteins to enable metal transfer has been highlighted previously [102].
In either case, the reaction did not lead to the complete demetallation at the chosen EDTA ratio, a finding in accordance with the previous work on wheat $\mathrm{E}_{\mathrm{C}}$ [93]. Inspection of the entire timecourse indicates that the reaction with MT4a was essentially completed after $25 \mathrm{~min}$, whilst the period required to reach equilibrium was, under these conditions, at least four times longer for MT4b. Thus, metal ions are lost much faster from $\mathrm{Zn}_{6} \mathrm{MT} 4 \mathrm{a}$ than from $\mathrm{Zn}_{6} \mathrm{MT} 4 \mathrm{~b}$ also when EDTA is provided in stoichiometric amounts. Comparison of the mass spectra at the $12 / 13 \mathrm{~min}$ time point further corroborates this conclusion: the $\mathrm{Zn}_{6}$ species was still dominating MT4b speciation, along with low intensity peaks for $Z_{5}$, $\mathrm{Zn}_{4}, \mathrm{Zn}_{3}, \mathrm{Zn}_{2}$, and $\mathrm{Zn}_{1}$ species, whilst the most abundant species for MT4a was already $Z_{3}$, with the $Z_{6}$ species reduced to $<10 \%$ relative abundance. Furthermore, the speciation for the proteins differed during as well as at the end of the reactions. One salient feature is the almost complete absence of a $Z_{5}$ species for MT4a, whilst this was clearly observable for MT4b during the first $60 \mathrm{~min}$ of the reaction. Another important observation is the dominance of the $\mathrm{Zn}_{3}$ MT4a species throughout the reaction-including after equilibration for $22 \mathrm{~h}$. In contrast, the most abundant species for MT4b at this time point was the $\mathrm{Zn}_{2}$ species, although the $\mathrm{Zn}_{3}$ species was the second-most abundant metalloform. In addition, although the MT4a apo form was observed after 13 min already, its relative abundance remained well below 10\% (Fig. 6). The MT4b apo form first appeared at $60 \mathrm{~min}$, but also remained at low relative abundance.

The most important conclusion from the ESI-MS experiments is that metal ions are lost in a fairly non-cooperative fashion from MT4b, with no evidence for any "cluster collapse" after removal of the first $\mathrm{Zn}$ ion: Cooperative metal loss is expected to lead to greatly diminished abundance of species corresponding to partially loaded domains [82-85]; therefore, a very different pattern of abundances for the various under-metallated species during the reaction may be expected if cooperativity was in effect. In contrast, the peculiar absence of the $\mathrm{Zn}_{5}$ species in MT4a indicates that loss of the first $\mathrm{Zn}$ ion facilitates loss of a second one, leading to a brief build-up of the $\mathrm{Zn}_{4}$ species, which, however, also reacts fairly rapidly to give the $\mathrm{Zn}_{3}$ species.

To shed some light on the likely locations of the most reactive $\mathrm{Zn}$ sites and remaining $\mathrm{Zn}$ ions, and whether the two domains in each protein displayed different reactivities that may help explain the observations from UV-Vis spectroscopy and ESI-MS, $1 \mathrm{D}^{1} \mathrm{H}$ (Supplementary Fig. S3) and $2 \mathrm{D}\left[{ }^{1} \mathrm{H},{ }^{15} \mathrm{~N}\right]$ HSQC NMR spectroscopy (Fig. 7) was employed. 2D $\left[{ }^{1} \mathrm{H},{ }^{15} \mathrm{~N}\right] \mathrm{HSQC}$ spectroscopy has the advantage of eliminating spectral overlap, enhancing the ability to extract residue-specific information throughout the fingerprint region, whereas $1 \mathrm{D}^{1} \mathrm{H}$ NMR spectroscopy allows faster sampling of time points, and also yields information on relevant side-chain protons, for example the aromatic 
protons of His residues. Moreover, 1D spectra also contain quantitative information on the ratio between free and $\mathrm{Zn}$ bound EDTA. Both 1D and 2D data sets reveal that metal transfer to EDTA is accompanied by the disappearance of resolved backbone $\mathrm{NH}$ peaks, consistent with the unfolding of the proteins. The higher initial reactivity of $\mathrm{Zn}_{6} \mathrm{MT} 4 \mathrm{a}$ compared to $\mathrm{Zn}_{6} \mathrm{MT} 4 \mathrm{~b}$ was also evident from both data sets (Fig. 7 and Supplementary Fig. 3), especially regarding the very first time points in each case (ca. $5 \mathrm{~min}$ for the 1D data, and ca. $10 \mathrm{~min}$ for the $2 \mathrm{D}$ data). For both proteins, the presence of substantial amounts of free EDTA at the end of the reactions monitored by $1 \mathrm{D}{ }^{1} \mathrm{H}$ NMR (Supplementary Fig. S3) confirmed that equimolar EDTA was insufficient for complete demetallation.

The 2D NMR data show that for both proteins, domain I was initially less reactive than domain II, as in both cases, domain I residues were visible at the 10 and 17 min time points-whereas this was not the case for domain II (see below). In fact, a proportion of the domain I resonances persisted throughout the reaction for both proteins, albeit at clearly diminished intensities (Supplementary Fig. S4). The decreasing intensities for both domains indicate that in principle, both domains of both proteins are able to react with EDTA simultaneously, albeit at different rates-at least when EDTA is supplied in equimolar amounts. Interestingly, the intensity of the domain I resonances for MT4a even increased slightly after the 25 min time point, perhaps an indication for slow metal redistribution after the initial removal from domain I. This observation highlights that the kinetic product(s) of the reaction with EDTA may not necessarily be identical to the thermodynamic products. It is somewhat surprising that this redistribution/refolding seems to be a slow process, as it has been pointed out that MT metallospecies, due to fast on/off rates, usually equilibrate within milliseconds with each other [60]. Either way, the persistence of domain I resonances-only observed in the more sensitive 2D HSQC experiment-suggests that for both proteins, at least some of the $\mathrm{Zn}_{2}$ (and $\mathrm{Zn}_{3}$ ) species observed by ESI-MS correspond to fully metallated domain I.

Significant differences between the two homologues were observed for domain II. For MT4a, all domain II resonances had already been lost after $10 \mathrm{~min}$ (Fig. 7a). A corresponding 1D data set indicates that ca. 3.8 equivalents of EDTA had reacted by this time already (Supplementary Fig. S3). In contrast, the 2D MT4b data show resolved domain II resonances at the same $10 \mathrm{~min}$ point. It is noteworthy that all four ligand residues that form the mononuclear site (His43, His51, Cys57, and Cys59) were still clearly resolved. The residues maintaining ordered structure also included all remaining four Cys residues in the second Cys-rich stretch of the MT4b sequence (Cys46, Cys48, Cys52, and Cys54). The previous work on wheat $\mathrm{E}_{\mathrm{C}}$ mutant proteins had indicated that the Zn-bound status of the equivalent of His51 was critical to structuring the entire domain II via crosstalk to these four residues [61]. Residues Cys77, Cys79, and Cys82 were still present as well. The fact that resonances for the mononuclear site of domain II remained visible in the initial stages, together with the disappearance of the resonances for Cys71 and 73, may be taken to suggest that the initial zinc(II) release from $\mathrm{Zn}_{6} \mathrm{MT} 4 \mathrm{~b}$ occurred not from the mononuclear site, but preferentially from the three-metal cluster, although we would caution that resonances for the three residues Cys71, Thr72, and Cys 73 were already weaker in the unreacted protein.

In summary, the likely origin of the different metal transfer dynamics of MT4a and MT4b resides predominantly in domain II, with MT4a showing more rapid and more cooperative metal transfer to EDTA. In the following section, we will seek to identify the cause for this difference.

\section{Discussion}

Studying metallospecies and protein folding as affected by proton-driven demetallation has revealed that for both MT4a and MT4b, domain II is more $\mathrm{pH}-$ labile than domain I. A re-analysis of published data for wheat $\mathrm{E}_{\mathrm{C}}[45]$ indicates that this is also the case for the latter protein. $\mathrm{E}_{\mathrm{C}}$ produced a prominent $\mathrm{Zn}_{4}$ species at moderately acidic $\mathrm{pH}$ that coexisted with either the $\mathrm{Zn}_{6}$ species (pH 5.5) or the $\mathrm{Zn}_{2}$ and apo species ( $\mathrm{pH} 4.0$ ), whilst $\mathrm{Zn}_{5}, \mathrm{Zn}_{3}$ or $\mathrm{Zn}_{1}$ were much less abundant; yet, the loss of two zinc(II) ions from $\mathrm{Zn}_{6} \mathrm{E}_{\mathrm{C}}$ did not correspond to cooperative demetallation of the $\mathrm{Zn}_{2}$ domain I as might have been concluded, as the NMR signals from this domain persisted at lower $\mathrm{pH}$ than those for domain II [103]. Therefore, neither wheat $\mathrm{E}_{\mathrm{C}}$ nor $A$. thaliana MT4b lose their domain II-bound zinc(II) ions cooperatively as far as proton-driven metal loss is concerned. There is some indication for moderately cooperative loss of zinc(II) from domain II of MT4a, where the $\mathrm{Zn}_{2}$ species that most likely corresponds to fully metallated domain I was most abundant at $\mathrm{pH}$ 4.9. Furthermore, since the backbone amide ${ }^{1} \mathrm{H}$ NMR signals for the $\mathrm{Zn}_{6}$ forms of either protein neither shift nor broaden, the species observed are unlikely to be in chemical exchange with other species. Hence, the decreases in intensity correspond to the decrease in the concentration of the fully metallated domains in both cases. This also means that the $\mathrm{Zn}_{4}$ or $\mathrm{Zn}_{5}$ species for MT4b, which are present at significant amounts above the $\mathrm{pH}(1 / 2)$, do not seem to give rise to new dispersed NMR signals. Hence, partially metallated domains are likely to be structurally disordered.

Regarding metal transfer dynamics, we will first attempt to contextualise and integrate the results from the three techniques employed to monitor the reactions with EDTA. The UV-Vis timecourse data revealed monophasic reaction kinetics for MT4b, and biphasic kinetics for MT4a, with the 
first phase of the latter being considerably faster than the single phase for MT4b. For full-length mammalian MTs, different phases were ascribed to differences in the reactivity of their two domains $[31,93,95] . \mathrm{Zn}_{6} \mathrm{E}_{\mathrm{C}}$ from wheat appeared to display triphasic reaction kinetics, although the fastest step was only discernible at lower EDTA:protein ratios, and could hence not be quantified under appropriate pseudo-first-order conditions [96]. This fastest step was suggested to correspond to the loss of up to $3 \mathrm{Zn}$ ions, followed by a second slower phase with a rate of ca. $5 \times 10^{-4} \mathrm{~s}^{-1}$, between the rates for the fastest observed step for MT4a and for the only step seen for MT4b. In the case of wheat $E_{C}$, it was not possible to determine whether the most reactive $\mathrm{Zn}$ ions originated from domain I or II. The slowest third phase observed for wheat $\mathrm{E}_{\mathrm{C}}$ was attributed to protein degradation. This did not appear to be a major contribution within the timeframe of the present experiments. Furthermore, monitoring the reaction at lower EDTA:protein ratios for MT4a or MT4b gave no clear indication of whether a faster step for either MT4a or MT4b exists (Supplementary Fig. S2), but comparison of the time required to completely deplete the $\mathrm{Zn}_{6}$ form (25 min for MT4a as well as for wheat $\mathrm{E}_{\mathrm{C}}$, 70 min for MT4b) suggests that $\mathrm{Zn}_{6} \mathrm{MT} 4 \mathrm{~b}$ reacted considerably more slowly than either wheat $\mathrm{Zn}_{6} \mathrm{E}_{\mathrm{C}}$ or $\mathrm{Zn}_{6} \mathrm{MT} 4 \mathrm{a}$; thus, it is most likely that the fast component observed for wheat $\mathrm{E}_{\mathrm{C}}$ does not occur for MT4b.

In the case of mammalian MTs, kinetic data were compatible with removal of the first metal ion being the ratedetermining step for the reactivity of the entire cluster, with the loss of the subsequent cluster ions being much faster than the first-in essence, metal loss was cooperative within the individual domains [31, 94]. In contrast, our native ESI-MS data indicate that zinc(II) loss from MT4b is largely non-cooperative, as the full range of species was observed with detectable and comparable intensities (Fig. 6). For MT4a, the absence of the $\mathrm{Zn}_{5}$ MT4a species points to a degree of cooperativity-but the NMR results indicate that the observed $\mathrm{Zn}_{4}$ species do not correspond to fully loaded domain II, but instead include species with fully loaded domain I. This also means that these $\mathrm{Zn}_{4}$ species harbour domain II with two $\mathrm{Zn}$ ions bound-reminiscent of the $\mathrm{Zn}_{4}$ species observed for wheat $\mathrm{E}_{\mathrm{C}}$ at moderately acidic $\mathrm{pH}$. Although these under-metallated species have been generated in different ways, it is clear that the three cluster sites are not equivalent in either MT4a or wheat $\mathrm{E}_{\mathrm{C}}$-irrespective of at which sites the remaining two ions are bound. In any case, the clear occurrence of the $\mathrm{Zn}_{4} \mathrm{MT} 4 \mathrm{a}$ species indicates that removal of the first ion did not lead to "cluster collapse" for MT4a either, although it is clear that the four zinc(II) ions bound to domain II are more prone to transfer than the two in domain I.

Finally, the NMR results clearly indicate that in both proteins, both domains are capable of metal transfer, a conclusion that was also reached for wheat $\mathrm{E}_{\mathrm{C}}$ [97]. Thus, in the case of plant MTs, the simple kinetics displayed may not always be a consequence of single rates being observed for each domain, but of similar rates for several different sites in different metallated species. Thus, it may be concluded that the initial reactivities of the two domains in MT4b are more similar to each other, and hence, any small differences in reactivity are not resolved at low protein concentration and 100-fold excess of EDTA. In turn, the biphasic kinetics observed for MT4a may be a reflection of the distinct reactivities of the two domains, as observed by NMR spectroscopy, with the fast phase dominated by domain II losing 3-4 zinc(II) ions. Thus, the most salient finding from integrating UV-Vis and NMR results is the comparatively high reactivity of domain II of $\mathrm{Zn}_{6} \mathrm{MT} 4 \mathrm{a}$.

The differences observed between MT4a and MT4b must ultimately arise from differences in their sequences (as highlighted in Fig. 2c), with consequences for their 3D structures and protein dynamics. Our NMR spectroscopic studies suggested that there were no large differences in the reactivity of the two domains I, but that domain II is responsible for the most significant differences in reactivity. Therefore, this discussion will largely focus on the latter domain, but will also include a brief inspection of the two domains I.

Structural effects of differences in the primary structures are reflected in the chemical shift comparison shown in Fig. 2c. It is evident that the largest differences in backbone shifts are observed where residues are not conserved. For these particular residues (highlighted in red), this is, in the first instance, a consequence of their different chemistry that impacts on their random-coil chemical shifts, and hence also on their chemical shifts in a folded protein. This is particularly obvious where one of the proteins harbours a glycine residue, as Gly backbone amide ${ }^{15} \mathrm{~N}$ chemical shifts are very different to those of most other amino acids. To a certain degree, differences in a given position will also impact on the directly adjacent residues. Therefore, the seemingly large chemical shift differences for some of the red residues and their neighbours are not remarkable per se, but can be used as a visual aid to pinpoint potential areas of interest.

Within domain I, two potentially important substitutions concern S15/R15 and N26/E26 (the latter residues are highlighted in grey as they could not be assigned for either protein). Taken together, these two substitutions do not alter the overall charge of the domain. To discern whether one might expect an effect of these substitutions on the immediate environment of the zinc(II) ions, we have generated homology models of the two domains I, based on the published structure of the wheat $E_{C} \gamma$ domain [58]. Inspection of the surface of the side from which the two zinc(II) ions are accessible reveals no major differences in surface potential near the metal ions (Fig. 8), in broad agreement with our experimental observations. 

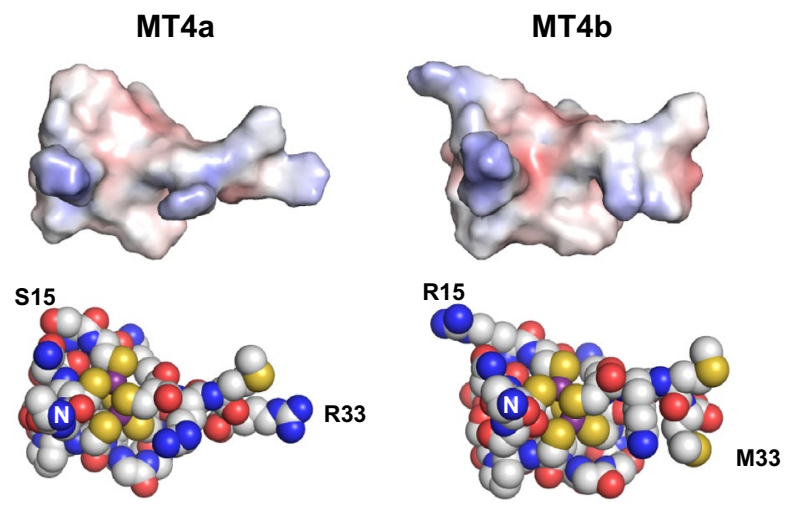

Fig. 8 Comparison of electrostatic potential surfaces and space-fill models of domain I. The models are oriented to show the zinc(II) ions from the most accessible side. The long presumably disordered $\mathrm{N}$-terminal tails have been removed, with the first residue depicted being Ala10 in both cases. This has led to an artificial positive charge at the new N-terminal residue; since the main purpose of this analysis was the comparison between MT4a and MT4b, we have refrained from introducing an artificial N-terminal acyl cap. The slight increase in negative charge in the vicinity of the metal cluster in MT4b originates from differences in the orientation of the backbone carbonyl oxygens of residues G11/S11; this is a consequence of the modelling process and should not be over-interpreted. Residues N26 and E26 are at the back of the molecules. Neither the S15/R15, nor the N26/ E26, or indeed the M33/R33 substitutions have a major impact on electrostatics around the zinc(II) sites. The surfaces are coloured by electrostatic potential as calculated by APBS, using \pm 5.0 as maximal negative/positive potential, respectively. Carbon, oxygen, and nitrogen atoms are labelled in CPK mode, with $\mathrm{Zn}$ ions in purple and sulfur atoms in yellow

Within domain II, the most remarkable dissimilarities occur around the first histidine residue (His42/His43). MT4a harbours a GHMV (41-44) motif, whilst for MT4b, the sequence is EHNT (42-45). Indeed, many type 4 MTs have the equivalent of Glu42 (Fig. 1). It can be anticipated that a negative charge may somewhat screen the mononuclear site against attack by nucleophiles-i.e., any reagent with a negative (partial) charge, which is of course also a property for any metal ligand including EDTA and potentially zinc(II) acceptor proteins. To examine the plausibility of this hypothesis, homology models of domain II of MT4a and MT4b have been generated based on the published structure of the beta-E domain of wheat $E_{C}$ [58]. In both MT4a and MT4b, the mononuclear site is characterised by a slightly positive surface potential, especially when the most accessible side of the site is considered (Fig. 9). Besides the zinc(II) ion itself, another contributor to positive charge in this region is the fairly well-conserved Lys60/61. Although the differences appear to be subtle, it is evident that the mononuclear site in MT4a is slightly more positive than that in MT4b. The reduced positive charge in MT4b is likely a consequence of longer range effects of Glu42. We propose that more positive
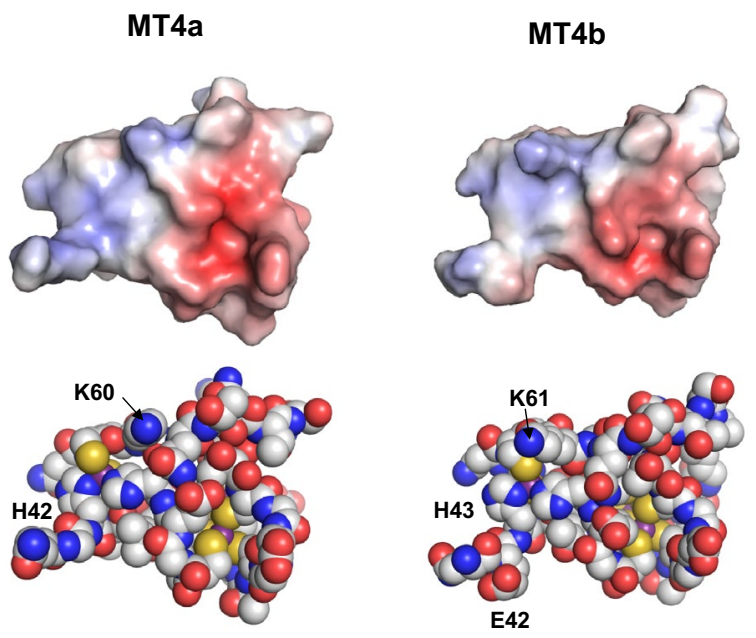

Fig. 9 Comparison of electrostatic surfaces and space-fill models of domain II. The models are oriented to show the mononuclear site (indicated by the H42/H43 labels) from its most accessible side. In contrast to the $\mathrm{Zn}_{3} \mathrm{Cys}_{9}$ cluster, around which there is an accumulation of negative charge, the mononuclear site is characterised by positive surface potential which may facilitate nucleophilic attack as well as complex formation with a negatively charged partner molecule. The models suggest that besides the zinc(II) ion, K60/61 also contributes to positive charge, and that the reduction in positive potential in MT4b is attributable to E42. The surfaces are coloured by electrostatic potential as calculated by APBS, using \pm 5.0 as maximal negative/positive potential, respectively. Carbon, oxygen and nitrogen atoms are labelled in CPK mode, with $\mathrm{Zn}$ ions in purple and sulfur atoms in yellow

charge around a zinc(II) site may facilitate approach of the negatively charged carboxylate groups of EDTA, and hence, the absence of the equivalent of Glu42 is likely to render the mononuclear zinc(II) ion in MT4a more reactive than that in MT4b. The electrostatic surface images also suggest that the $\mathrm{Zn}_{3} \mathrm{Cys}_{9}$ clusters are surrounded by substantial negative charge. This is mostly a consequence of the formal -3 charge of such clusters, which is not fully compensated by the presence of the two lysine residues in this domain. It should be noted that the side-chain conformations of lysine residues in our models are variable, and in solution would be quite flexible as well. It is, therefore, possible that their positive charges are at least occasionally closer to the negatively charged clusters in the vicinity, and this may in principle reduce average negative charge in certain areas to some degree, and thus facilitate nucleophilic attack.

Comparing electrostatics for all likely points of EDTA binding and nucleophilic attack (Figs. 8, 9), the mononuclear site in MT4a is the most positively charged, in agreement with our combined observations from UV-Vis, ESI-MS, and NMR spectroscopy. The next reactive site appears to be the mononuclear site in MT4b, also in broad agreement with our data. 
The above considerations are based on the hypothesis that bimolecular assemblies are required for efficient metal transfer. Indeed, such assemblies were observed in this work by ESI-MS, and electrostatics are undoubtedly important for understanding the likelihood for their formation. However, another critical contributor to metal lability in MTs is protein dynamics. Although we have not carried out extensive NMR-based backbone dynamics measurements, the HSQC spectra shown in Figs. 2a, b and 7, in conjunction with our sequential assignments (Fig. 2c), allow some pertinent qualitative observations. The HSQC spectra of MT4a (Figs. 2a, 7) were consistently characterised by a larger amount of unresolved intensity in the random-coil region in the middle of the spectra, and numerous domain II residues gave rise to comparatively weak signals, whilst this was not the case for MT4a domain I resonances. This strongly suggests that domain II of MT4a is inherently more flexible than domain II of MT4b. One consequence of this increased flexibility is highlighted by the grey bars and letters in Fig. 2c. The corresponding residues are those that could not be assigned for MT4a, but for MT4b. The difficulties in identifying the respective cross-peaks in the MT4a data indicate that either the chemical environment, or the backbone dynamics, or, indeed, both are substantially different between MT4a and MT4b, as otherwise, there should have been an unassigned peak in the MT4a HSQC spectrum with similar shifts to an assigned peak in the MT4b spectrum. For Cys72 (MT4a), this can be ruled out most definitively (due to the extreme low-field shift $(9.85 \mathrm{ppm})$ of the Cys73 proton in MT4b). This means that structure and/or dynamics of this particular stretch differ significantly between the two proteins. We also note that the ${ }^{1} \mathrm{H}$ resonance for Cys73 in MT4b is quite weak and broad; so in MT4b, this region is characterised by higher flexibility than the remainder of domain II. It is possible that the same is true for this region in MT4a, which coupled with an inherently higher flexibility of the entire domain, may lead to dynamics on the intermediate exchange regime for Cys72 in MT4a. It is noteworthy that the primary sequences in this stretch are identical; therefore, differences observed here must be a consequence of changes elsewhere in the protein sequence. It is fairly unlikely that the conservative Ser80/Thr81 or Thr83/Ala84 substitutions would have such a remarkable effect on backbone dynamics elsewhere in the domain; the more likely suspects are again the substitutions around His42/43. Asn44 and Thr45 in MT4b are both hydrophilic residues capable of engaging in hydrogen bonding; indeed, in our model, the amide side chain of Asn44 has an H-bond with that of Asn55 (not shown). In contrast, such stabilising H-bonds are not possible for Met43 or Val44. These two residues together form a small hydrophobic patch on the protein surface that is rather unusual for an MT. Whilst the interaction between these two residues may be mutually stabilising, hydrophobic sidechains on a protein surface are inherently unfavourable, and thus, we hypothesise that these two residues are significant contributors to the higher structural flexibility of domain II in MT4a. Such increased flexibility is likely to increase the lability of bound metal ions, and this may be a further contribution to the faster metal transfer dynamics of MT4a-and this may not only affect transfer from the mononuclear site, but also from the $\mathrm{Zn}_{3} \mathrm{Cys}_{9}$ cluster.

\section{Conclusions}

The suggested biological function of type 4 MTs includes zinc(II) donation to zinc(II)-requiring proteins, peptides, or small molecules during seed maturation and/or germination $[37,50,55]$. This concept is supported by in planta studies in A. thaliana that demonstrated MT4 protein localisation in the embryo [55]. More recently, type 4 MT protein was also detected in the aleurone layer of maturing and mature seeds of the monocotyledonous plant barley $[52,104]$. This tissue is important for nutrient transport and seed filling. Taken together, these in vivo studies strongly support a role of type 4 MTs in supplying zinc(II) to nascent zinc(II)-requiring proteins, during embryogenesis, seed maturation, and/or during germination. It is, therefore, of general importance to investigate their ability to transfer zinc(II) to suitable acceptor molecules. Our studies using EDTA as a model zinc(II) acceptor confirm that A. thaliana MT4a and MT4b principally fulfil essential criteria to act as cellular zinc(II) donors: at least some of their bound metals are bound in a fairly labile fashion, allowing zinc(II) transfer to EDTA to occur with rates comparable to those observed for other MTs. We note that another important aspect in this scenario is metal affinity, and that in the case of wheat $\mathrm{E}_{\mathrm{C}}$, it has been found that the average apparent binding constant for zinc(II) was particularly low at higher ionic strength $(\log K=8.6$ at $\mathrm{pH} 7.4$ and $I=105 \mathrm{mM}$ ) [45]. It is conceivable that such low affinity might favour metal transfer from the MT.

All our experiments started with fully metallated MTs. It may, however, be noted that there is increasing evidence that many MTs are only partially metallated in vivo. The prevalence of partially metallated MTs and their relevance in the cellular context has been pointed out repeatedly for mammalian MTs [29-31, 60, 84, 105, 106], but there are also several reports where under-metallated plant MT4 s have been isolated [52, 107]. Indeed, the stoichiometries found for sesame and barley were approximately 2-3 zinc(II) per protein, and based on our observations by ESI-MS and the high level of conservation in this domain (Fig. 1), it is tempting to speculate that these species might harbour fully loaded domains I. In the case of wheat $\mathrm{E}_{\mathrm{C}}[45,61]$ and the two homologues from A. thaliana, these are characterised by high thermodynamic stability, as judged from both $\mathrm{pH}$-dependent studies 
(Figs. 3, 4) and analysis of the end products of the EDTA reactions (Figs. 6, 7).

However, the most intriguing finding of the current study concerns the differences observed between two closely similar homologues that both occur in the seeds of a single plant. In planta observations had suggested that $A$. thaliana MT4a and MT4b work cooperatively where the role of MT4a is to distribute zinc(II) via the vasculature and MT4b functions as a store for zinc(II) throughout the embryo [55]. Although no differences in zinc(II)-binding strength were evident as judged form the $\mathrm{pH}(1 / 2)$ values determined earlier [37], the faster kinetics for zinc(II) transfer from MT4a and the slower kinetics for MT4b align well with these suggestions. In particular, our NMR studies, coupled with inspection of homology models and their electrostatic surfaces, have identified the mononuclear $\mathrm{Cys}_{2} \mathrm{His}_{2}$ site and its surroundings as the lynchpin that governs the reactivity of these two type 4 MTs, with non-conservative substitutions around the first histidine residue playing a crucial role for electrostatics and overall backbone dynamics.

Ultimately, it is clear that also zinc(II) bound to MT4b will need to be mobilised; this may or may not occur through direct transfer to other proteins. Several other options for zinc(II) release from MTs exist; these include oxidative reactions with electrophiles such as peroxide or oxidised glutathione [80], but may also encompass proteolytic degradation of the protein, as shown for wheat $\mathrm{E}_{\mathrm{C}}$ [48]. In addition, changes in $\mathrm{pH}$ or ionic strength may also modulate zinc(II) release. Within this framework, it can be envisaged that the two MTs may transfer or release their cargo at different times, different locations, and perhaps to different acceptors. Given their different reactivities, it is also possible that in each case, the two domains may serve different purposes.

Acknowledgements We thank Prof. Peter Goldsbrough (Purdue University) for expression constructs for A. thaliana MT4a and MTb, the Royal Society (Olga Kennard Fellowship to CAB), the University of Warwick, and the Department of Chemistry (Chancellor's Scholarship to HTI). We also thank Dr. Ralf Schmid (University of Leicester) for help with calculations of electrostatic potentials, and Dr. Esther Martin for helpful discussions regarding mass spectrometry. Support by Advantage West Midlands and the European Regional Development Fund (Birmingham Science City) is gratefully acknowledged.

Open Access This article is distributed under the terms of the Creative Commons Attribution 4.0 International License (http://creativecommons.org/licenses/by/4.0/), which permits unrestricted use, distribution, and reproduction in any medium, provided you give appropriate credit to the original author(s) and the source, provide a link to the Creative Commons license, and indicate if changes were made.

\section{References}

1. Maret W (2013) Zinc biochemistry: from a single zinc(II) enzyme to a key element of life. Adv Nutr 4:82-91
2. Bertini I, Decaria L, Rosato A (2010) The annotation of full zinc(II) proteomes. J Biol Inorg Chem 15:1071-1078

3. King JC (2011) Zinc: an essential but elusive nutrient. Am J Clin Nutr 94:679S-684S

4. Prasad AS, Halsted JA, Nadimi M (1961) Syndrome of iron deficiency anemia, hepatosplenomegaly, hypogonadism, dwarfism and geophagia. Am J Med 31:532-546

5. Prasad AS (2013) Discovery of human zinc(II) deficiency: its impact on human health and disease. Adv Nutr 4:176-190

6. Gibson RS (2012) Zinc deficiency and human health: etiology, health consequences, and future solutions. Plant Soil 361:291-299

7. Cakmak I (2000) Possible roles of zinc(II) in protecting plant cells from damage by reactive oxygen species. New Phytol 146:185-205

8. Krämer U, Clemens S (2006) Functions and homeostasis of zinc(II), copper, and nickel in plants. In: Tamas MJ, Martinoia E (eds) Molecular biology of metal homeostasis and detoxification: from microbes to man. Springer, Berlin, pp 215-271

9. Sandstead HH (2013) Human zinc(II) deficiency: discovery to initial translation. Adv Nutr 4:76-81

10. Alloway BJ (2009) Soil factors associated with zinc(II) deficiency in crops and humans. Environ Geochem Health 31:537-548

11. Hotz C, Brown KH (2004) International Zinc Nutrition Consultative Group (IZiNCG) technical document no. 1. Assessment of the risk of zinc(II) deficiency in populations and options for its control. Food Nutr Bull 25:S94-S203

12. Wessells KR, Brown KH (2012) Estimating the global prevalence of zinc(II) deficiency: results based on zinc(II) availability in national food supplies and the prevalence of stunting. PLoS One 7:e50568

13. http://www.copenhagenconsensus.com/sites/default/files/cc08_ results_final_0.pdf. Accessed 20 Aug 2017

14. Bouis HE, Welch RM (2010) Biofortification-A sustainable agricultural strategy for reducing micronutrient malnutrition in the global south. Crop Sci 50:S20-S32

15. Welch RM (2002) Breeding strategies for biofortified staple plant foods to reduce micronutrient malnutrition globally. J Nutr 132:495S-499S

16. Clemens S (2014) Zn and Fe biofortification: the right chemical environment for human bioavailability. Plant Sci 225:52-57

17. Guerinot ML (2016) Micronutrients: supplementing seeds with zinc(II). Nat Plants 2:16060

18. Cakmak I (2008) Enrichment of cereal grains with zinc(II): agronomic or genetic biofortification? Plant Soil 302:1-17

19. Palmer CM, Guerinot ML (2009) Facing the challenges of $\mathrm{Cu}$, $\mathrm{Fe}$ and $\mathrm{Zn}$ homeostasis in plants. Nat Chem Biol 5:333-340

20. Blindauer CA, Schmid R (2010) Cytosolic metal handling in plants: determinants for zinc(II) specificity in metal transporters and metallothioneins. Metallomics 2:510-529

21. Ricachenevsky FK, Menguer PK, Sperotto RA, Fett JP (2015) Got to hide your $\mathrm{Zn}$ away: molecular control of $\mathrm{Zn}$ accumulation and biotechnological applications. Plant Sci 236:1-17

22. Gupta N, Ram H, Kumar B (2016) Mechanism of zinc(II) absorption in plants: uptake, transport, translocation and accumulation. Rev Environ Sci Bio-Technol 15:89-109

23. Walker EL, Waters BM (2011) The role of transition metal homeostasis in plant seed development. Curr Opin Plant Biol 14:318-324

24. Olsen LI, Palmgren MG (2014) Many rivers to cross: the journey of zinc(II) from soil to seed. Front Plant Sci 5:30

25. Olsen LI, Hansen TH, Larue C, Osterberg JT, Hoffmann RD, Liesche J, Kramer U, Surble S, Cadarsi S, Samson VA, Grolimund D, Husted S, Palmgren M (2016) Mother-plant-mediated pumping of zinc(II) into the developing seed. Nat Plants 2:16036 
26. Cakmak I, Kalayci M, Kaya Y, Torun AA, Aydin N, Wang Y, Arisoy Z, Erdem H, Yazici A, Gokmen O, Ozturk L, Horst WJ (2010) Biofortification and localization of zinc(II) in wheat grain. J Agric Food Chem 58:9092-9102

27. Persson DP, de Bang TC, Pedas PR, Kutman UB, Cakmak I, Andersen B, Finnie C, Schjoerring JK, Husted S (2016) Molecular speciation and tissue compartmentation of zinc(II) in durum wheat grains with contrasting nutritional status. New Phytol 211:1255-1265

28. Krezel A, Maret W (2016) The biological inorganic chemistry of zinc(II) ions. Arch Biochem Biophys 611:3-19

29. Krezel A, Maret W (2006) Zinc-buffering capacity of a eukaryotic cell at physiological pZn. J Biol Inorg Chem 11:1049-1062

30. Krezel A, Maret W (2008) Thionein/metallothionein control $\mathrm{Zn}(\mathrm{II})$ availability and the activity of enzymes. J Biol Inorg Chem 13:401-409

31. Petering DH, Mahim A (2017) Proteomic high affinity $\mathrm{Zn}^{2+}$ trafficking: where does metallothionein fit in? Int J Mol Sci 18:1289

32. Feng W, Cai J, Pierce WM, Franklin RB, Maret W, Benz FW, Kang YJ (2005) Metallothionein transfers zinc(II) to mitochondrial aconitase through a direct interaction in mouse hearts. Biochem Biophys Res Commun 33:853-858

33. Jiang LJ, Maret W, Vallee BL (1998) The glutathione redox couple modulates zinc(II) transfer from metallothionein to zinc(II)depleted sorbitol dehydrogenase. Proc Natl Acad Sci USA 95:3483-3488

34. Jacob C, Maret W, Vallee BL (1998) Control of zinc(II) transfer between thionein, metallothionein, and zinc(II) proteins. Proc Natl Acad Sci USA 95:3489-3494

35. Cobbett C, Goldsbrough P (2002) Phytochelatins and metallothioneins: roles in heavy metal detoxification and homeostasis. Annu Rev Plant Biol 53:159-182

36. Grennan AK (2011) Metallothioneins, a diverse protein family. Plant Physiol 155:1750-1751

37. Leszczyszyn OI, Imam HT, Blindauer CA (2013) Diversity and distribution of plant metallothioneins: a review of structure, properties and functions. Metallomics 5:1146-1169

38. Robinson NJ, Thurman DA (1986) Involvement of a metallothionein-like copper complex in the mechanism of copper tolerance in Mimulus guttatus. Proc R Soc B Biol Sci 227:493-501

39. Lane B, Kajioka R, Kennedy T (1987) The wheat-germ Ec protein is a zinc(II)-containing metallothionein. Biochem Cell Biol 65:1001-1005

40. Freisinger E (2008) Plant MTs-long neglected members of the metallothionein superfamily. Dalton Trans 6663-6675

41. Freisinger E (2009) Metallothioneins in plants. In: Sigel A, Sigel H, Sigel RKO (eds) Metal ions in life sciences, vol 5. Royal Society of Chemistry, Cambridge, pp 107-153

42. Freisinger E (2011) Structural features specific to plant metallothioneins. J Biol Inorg Chem 16:1035-1045

43. Tomas M, Pagani MA, Andreo CS, Capdevila M, Atrian S, Bofill R (2015) Sunflower metallothionein family characterisation. Study of the Zn(II)- and Cd(II)-binding abilities of the HaMT1 and HaMT2 isoforms. J Inorg Biochem 148:35-48

44. Tomas M, Tinti A, Bofill R, Capdevila M, Atrian S, Torreggiani A (2016) Comparative Raman study of four plant metallothionein isoforms: insights into their $\mathrm{Zn}$ (II) clusters and protein conformations. J Inorg Biochem 156:55-63

45. Leszczyszyn OI, Schmid R, Blindauer CA (2007) Toward a property/function relationship for metallothioneins: histidine coordination and unusual cluster composition in a zinc(II)-metallothionein from plants. Proteins Struct Funct Bioinform 68:922-935

46. Peroza EA, Freisinger E (2007) Metal ion binding properties of Triticum aestivum E-c-1 metallothionein: evidence supporting two separate metal thiolate clusters. J Biol Inorg Chem $12: 377-391$
47. Tarasava K, Chesnov S, Freisinger E (2016) Oxidation of the $\mathrm{N}$-terminal domain of the wheat metallothionein E-c-1 leads to the formation of three distinct disulfide bridges. Biopolymers 106:295-308

48. Peroza EA, Cabral AD, Wan XQ, Freisinger E (2013) Metal ion release from metallothioneins: proteolysis as an alternative to oxidation. Metallomics 5:1204-1214

49. Tarasava K, Loebus J, Freisinger E (2016) Localization and spectroscopic analysis of the $\mathrm{Cu}(\mathrm{I})$ binding site in wheat metallothionein E-c-1. Int J Mol Sci 17:371

50. Kawashima I, Kennedy TD, Chino M, Lane BG (1992) Wheat Ec metallothionein genes. Like mammalian zinc(II)(2+) metallothionein genes, wheat zinc(II)(2+) metallothionein genes are conspicuously expressed during embryogenesis. Eur J Biochem 209:971-976

51. Guo WJ, Bundithya W, Goldsbrough PB (2003) Characterization of the Arabidopsis metallothionein gene family: tissue-specific expression and induction during senescence and in response to copper. New Phytol 159:369-381

52. Hegelund JN, Schiller M, Kichey T, Hansen TH, Pedas P, Husted S, Schjoerring JK (2012) Barley metallothioneins: MT3 and MT4 are localized in the grain aleurone layer and show differential zinc(II) binding. Plant Physiol 159:1125-1137

53. Tomas M, Pagani MA, Andreo CS, Capdevila M, Bofill R, Atrian S (2014) His-containing plant metallothioneins: comparative study of divalent metal-ion binding by plant MT3 and MT4 isoforms. J Biol Inorg Chem 19:1149-1164

54. Guo WJ, Meetam M, Goldsbrough PB (2008) Examining the specific contributions of individual Arabidopsis metallothioneins to copper distribution and metal tolerance. Plant Physiol 146:1697-1706

55. Ren Y, Liu Y, Chen H, Li G, Zhang X, Zhao J (2012) Type 4 metallothionein genes are involved in regulating $\mathrm{Zn}$ ion accumulation in late embryo and in controlling early seedling growth in Arabidopsis. Plant Cell Environ 35:770-789

56. Rodriguez-Llorente ID, Perez-Palacios P, Doukkali B, Caviedes MA, Pajuelo E (2010) Expression of the seed-specific metallothionein MT4a in plant vegetative tissues increases $\mathrm{Cu}$ and $\mathrm{Zn}$ tolerance. Plant Sci 178:327-332

57. Peroza EA, Schmucki R, Güntert P, Freisinger E, Zerbe O (2009) The beta(E)-domain of wheat E(c)-1 metallothionein: a metal-binding domain with a distinctive structure. J Mol Biol 387:207-218

58. Loebus J, Peroza EA, Blüthgen N, Fox T, Meyer-Klaucke W, Zerbe O, Freisinger E (2011) Protein and metal cluster structure of the wheat metallothionein domain gamma-E(c)-1: the second part of the puzzle. J Biol Inorg Chem 16:683-694

59. Tarasava K, Johannsen S, Freisinger E (2013) Solution structure of the circular gamma-domain analog from the wheat metallothionein E-c-1. Molecules 18:14414-14429

60. Sutherland DEK, Stillman MJ (2011) The "magic numbers" of metallothionein. Metallomics 3:444-463

61. Leszczyszyn OI, White CRJ, Blindauer CA (2010) The isolated Cys(2)His(2) site in $\mathrm{E}_{\mathrm{C}}$ metallothionein mediates metal-specific protein folding. Mol BioSyst 6:1592-1603

62. Zhou JM, Goldsbrough PB (1995) Structure, organisation and expression of the metallothionein gene family in Arabidopsis. Mol Gen Genet 248:318-328

63. Palacios O, Atrian S, Capdevila M (2011) Zn- and Cu-thioneins: a functional classification for metallothioneins? J Biol Inorg Chem 16:991-1009

64. Kowald GR, Stürzenbaum SR, Blindauer CA (2016) Earthworm Lumbricus rubellus MT-2: metal binding and protein folding of a true cadmium-MT. Int J Mol Sci 17:65

65. M'kandawire E, Mierek-Adamska A, Stürzenbaum SR, Choongo K, Yabe J, Mwase M, Saasa N, Blindauer CA (2017) 
Metallothionein from wild populations of the African Catfish Clarias gariepinus: from sequence, protein expression and metal binding properties to transcriptional biomarker of metal pollution. Int J Mol Sci 18:1548

66. Palacios Ò, Jiménez-Martí E, Niederwanger M, Gil-Moreno S, Zerbe O, Atrian S, Dallinger R, Capdevila M (2017) Analysis of metal-binding features of the wild type and two domain-truncated mutant variants of Littorina littorea metallothionein reveals its Cd-specific character. Int J Mol Sci 18:1452

67. Leszczyszyn OI, Zeitoun-Ghandour S, Stürzenbaum SR, Blindauer CA (2011) Tools for metal ion sorting: in vitro evidence for partitioning of zinc(II) and cadmium in C. elegans metallothionein isoforms. Chem Commun 47:448-450

68. Zeitoun-Ghandour S, Charnock JM, Hodson ME, Leszczyszyn OI, Blindauer CA, Stürzenbaum SR (2010) The two Caenorhabditis elegans metallothioneins (CeMT-1 and CeMT-2) discriminate between essential zinc(II) and toxic cadmium. FEBS J 277:2531-2542

69. Artells E, Palacios O, Capdevila M, Atrian S (2013) Mammalian MT1 and MT2 metallothioneins differ in their metal binding abilities. Metallomics 5:1397-1410

70. Tomas M, Domenech J, Capdevila M, Bofill R, Atrian S (2013) The sea urchin metallothionein system: comparative evaluation of the SpMTA and SpMTB metal-binding preferences. FEBS Open Bio 3:89-100

71. Palacios O, Perez-Rafael S, Pagani A, Dallinger R, Atrian S, Capdevila M (2014) Cognate and noncognate metal ion coordination in metal-specific metallothioneins: the Helix pomatia system as a model. J Biol Inorg Chem 19:923-935

72. Vašák M (1995) Standard isolation procedure for metallothionein. Methods Enzymol 205:41-44

73. Acharya C, Blindauer CA (2016) Unexpected interactions of the cyanobacterial metallothionein SmtA with uranium. Inorg Chem 55:1505-1515

74. Usha V, Lloyd AJ, Roper DI, Dowson CG, Kozlov G, Gehring K, Chauhan S, Imam HT, Blindauer CA, Besra GS (2016) Reconstruction of diaminopimelic acid biosynthesis allows characterisation of Mycobacterium tuberculosis $N$-succinyl-L,L-diaminopimelic acid desuccinylase. Sci Rep 6:23191

75. Goddard TD, Kneller DG SPARKY 3, University of California, San Francisco

76. Marti-Renom MA, Stuart AC, Fiser A, Sanchez R, Melo F, Sali A (2000) Comparative protein structure modeling of genes and genomes. Annu Rev Biophys Biomol Struct 29:291-325

77. Krivov GG, Shapovalov MV, Dunbrack RL (2009) Improved prediction of protein side-chain conformations with SCWRL4. Proteins 77:778-795

78. Vriend G (1990) WHAT IF-a molecular modeling and drug design program. J Mol Gr 8:52-56

79. Dolinsky TJ, Nielsen JE, McCammon JA, Baker NA (2004) PDB2PQR: an automated pipeline for the setup, execution, and analysis of Poisson-Boltzmann electrostatics calculations. Nucleic Acids Res 32:W665-W667

80. Blindauer CA (2014) Chapter 21 metallothioneins. In: Maret W, Wedd AG (eds) Binding, transport and storage of metal ions in biological cells. The Royal Society of Chemistry, Cambridge, UK, pp 606-665

81. Peroza EA, Al Kaabi A, Meyer-Klaucke W, Wellenreuther G, Freisinger E (2009) The two distinctive metal ion binding domains of the wheat metallothionein E(c)-1. J Inorg Biochem 103:342-353

82. Gehrig PM, You CH, Dallinger R, Gruber C, Brouwer M, Kägi JHR, Hunziker PE (2000) Electrospray ionization mass spectrometry of zinc(II), cadmium, and copper metallothioneins: evidence for metal-binding cooperativity. Protein Sci 9:395-402
83. Palumaa P, Eriste E, Njunkova O, Pokras L, Jornvall H, Sillard R (2002) Brain-specific metallothionein-3 has higher metal-binding capacity than ubiquitous metallothioneins and binds metals noncooperatively. Biochemistry 41:6158-6163

84. Sutherland DEK, Summers KL, Stillman MJ (2012) Noncooperative metalation of metallothionein 1a and its isolated domains with zinc(II). Biochemistry 51:6690-6700

85. Irvine GW, Stillman MJ (2016) Cadmium binding mechanisms of isolated domains of human MT isoform 1a: non-cooperative terminal sites and cooperative cluster sites. J Inorg Biochem 158:115-121

86. Chen SH, Russell WK, Russell DH (2013) Combining chemical labeling, bottom-up and top-down ion-mobility mass spectrometry to identify metal-binding sites of partially metalated metallothionein. Anal Chem 85:3229-3237

87. Chen SH, Chen LX, Russell DH (2014) Metal-induced conformational changes of human metallothionein-2A: a combined theoretical and experimental study of metal-free and partially metalated intermediates. J Am Chem Soc 136:9499-9508

88. Sutherland DEK, Willans MJ, Stillman MJ (2010) Supermetalation of the beta domain of human metallothionein 1a. Biochemistry 49:3593-3601

89. Rigby Duncan KE, Kirby CW, Stillman MJ (2008) Metal exchange in metallothioneins: a novel structurally significant $\mathrm{Cd}(5)$ species in the alpha domain of human metallothionein $1 \mathrm{a}$. FEBS J 275:2227-2239

90. Palumaa P, Tammiste I, Kruusel K, Kangur L, Jornvall H, Sillard R (2005) Metal binding of metallothionein- 3 versus metallothionein-2: lower affinity and higher plasticity. Biochim Biophys Acta Proteins Proteom 1747:205-211

91. Meloni G, Polanski T, Braun O, Vašák M (2009) Effects of $\mathrm{Zn}^{2+}$, $\mathrm{Ca}^{2+}$, and $\mathrm{Mg}^{2+}$ on the structure of $\mathrm{Zn}(7)$ metallothionein-3: evidence for an additional zinc(II) binding site. Biochemistry 48:5700-5707

92. Page R, Peti W, Wilson IA, Stevens RC, Wüthrich K (2005) NMR screening and crystal quality of bacterially expressed prokaryotic and eukaryotic proteins in a structural genomics pipeline. Proc Natl Acad Sci USA 102:1901-1905

93. Li TY, Kraker AJ, Shaw CF 3rd, Petering DH (1980) Ligand substitution reactions of metallothioneins with EDTA and apocarbonic anhydrase. Proc Natl Acad Sci USA 77:6334-6338

94. Shaw CF 3rd, Savas MM, Petering DH (1991) Ligand substitution and sulfhydryl reactivity of metallothionein. Methods Enzymol 205:401-414

95. Gan T, Munoz A, Shaw CF 3rd, Petering DH (1995) Reaction of ${ }^{111} \mathrm{Cd}_{7}$-metallothionein with EDTA. A reappraisal. J Biol Chem 270:5339-5345

96. Leszczyszyn OI, Evans CD, Keiper SE, Warren GZL, Blindauer CA (2007) Differential reactivity of individual zinc(II) ions in clusters from bacterial metallothioneins. Inorg Chim Acta 360:3-13

97. Leszczyszyn OI, Blindauer CA (2010) Zinc transfer from the embryo-specific metallothionein E-C from wheat: a case study. Phys Chem Chem Phys 12:13408-13418

98. Hathout Y, Fabris D, Fenselau C (2001) Stoichiometry in zinc(II) ion transfer from metallothionein to zinc(II) finger peptides. Int J Mass Spectrom 204:1-6

99. Zaia J, Fabris D, Wei D, Karpel RL, Fenselau C (1998) Monitoring metal ion flux in reactions of metallothionein and drugmodified metallothionein by electrospray mass spectrometry. Protein Sci 7:2398-2404

100. Pinter TBJ, Stillman MJ (2015) Putting the pieces into place: properties of intact zinc(II) metallothionein 1A determined from interaction of its isolated domains with carbonic anhydrase. Biochem J 471:347-356 
101. Pinter TBJ, Stillman MJ (2014) The zinc(II) balance: competitive zinc(II) metalation of carbonic anhydrase and metallothionein 1A. Biochemistry 53:6276-6285

102. Costello LC, Fenselau CC, Franklin RB (2011) Evidence for operation of the direct zinc(II) ligand exchange mechanism for trafficking, transport, and reactivity of zinc(II) in mammalian cells. J Inorg Biochem 105:589-599

103. Leszczyszyn OI (2008) PhD thesis, University of Warwick

104. Schiller M, Hegelund JN, Pedas P, Kichey T, Laursen KH, Husted S, Schjoerring JK (2014) Barley metallothioneins differ in ontogenetic pattern and response to metals. Plant Cell Environ $37: 353-367$
105. Krezel A, Maret W (2007) Dual nanomolar and picomolar $\mathrm{Zn}$ (II) binding properties of metallothionein. J Am Chem Soc 129:10911-10921

106. Rana U, Kothinti R, Meeusen J, Tabatabai NM, Krezoski S, Petering DH (2008) Zinc binding ligands and cellular zinc(II) trafficking: Apo-metallothionein, glutathione, TPEN, proteomic zinc(II), and Zn-Sp1. J Inorg Biochem 102:489-499

107. Chyan CL, Lee TT, Liu CP, Yang YC, Tzen JT, Chou WM (2005) Cloning and expression of a seed-specific metallothionein-like protein from sesame. Biosci Biotechnol Biochem 69:2319-2325 